\title{
Proton-Transfer Reactions of Dibasic Acids in Aqueous Solution: 3-Hydroxypyridine and Anthranillc Acld
}

\author{
Johannes Reiter, Anton Beyer, Martin Potschka, Peter Schuster,* \\ Institut für Theoretische Chemie und Strahlenchemie der Universität Wien, Währingerstrasse 17, A-1090 Wien, \\ Austria \\ Heinz Winkler, \\ Max-Planck-Institut für Biophysikalische Chemie, Postfach 2841, D-34 Göttingen, F.R.G.
}

Hans Ebeling, and E. U. Franck

Institut für Physikalische Chemie der Universität Karlsruhe, D-75 Karlsruhe, F.R.G. (Received: March 22, 1988)

\begin{abstract}
Reaction enthalpies and reaction volumes of proton-transfer reactions in aqueous solutions of 3-hydroxypyridine have been estimated by measuring UV-visible absorption spectra at different temperatures, pressures, and $\mathrm{pH}$ values. Using these results together with published thermodynamic and kinetic data, we have simulated the relaxation spectrum of the proton-transfer reactions of 3-hydroxypyridine in aqueous solution. The first process identified in our normal mode analysis is the relaxation of the well-known tautomeric equilibrium between the neutral form and the zwitterion, $A_{N}=A_{Z}$. The second relaxation process is the overall reaction $\mathrm{A}^{+}+\mathrm{A}^{-}=x \mathrm{~A}_{\mathrm{N}}+(2-x) \mathrm{A}_{\mathrm{Z}}$, with $x$ being roughly equal to unity. The amplitude of this relaxation is significantly smaller than that of the first. The third relaxation process consists of two branches. The first branch is the overall reaction $\mathrm{A}^{+}=x \mathrm{~A}_{\mathrm{N}}+(1-x) \mathrm{A}_{2}+\mathrm{H}^{+}, x \sim 0.5$, at $\mathrm{pH} \ll 7$, and the second branch is the overall reaction $x \mathrm{~A}_{\mathrm{N}}+(1-x) \mathrm{A}_{\mathrm{Z}}+\mathrm{OH}^{-}=\mathrm{A}^{-}+\mathrm{H}_{2} \mathrm{O}, x \sim 0.5$, at $\mathrm{pH} \gg 7$. The fourth relaxation process is more complicated than the others. It consists mainly of hydrolysis reactions at $\mathrm{pH} \ll 7$ and protolysis reactions at $\mathrm{pH} \gg 7$. This relaxation process can be neglected because of its small amplitude. In the second part of this work, we have measured the ultrasound absorption of aqueous solutions of anthranilic acid, and using the information obtained from the normal mode analysis of 3-hydroxypyridine, we present evidence for the intramolecular proton-transfer reaction $\mathrm{A}_{\mathrm{N}} \rightleftharpoons \mathrm{A}_{\mathrm{Z}}$. The sum of forward rate constant $k_{23}$ and reverse rate constant $k_{32}$ is about $9.3 \times 10^{6} \mathrm{~s}^{-1}$. With the literature value of 0.2 for the equilibrium constant, the rate constants are $k_{23} \sim 1.6 \times 10^{6} \mathrm{~s}^{-1}$ and $k_{32} \sim 7.8 \times 10^{6} \mathrm{~s}^{-1}$. In an earlier study, White and Slutsky had found no evidence for this reaction. However, because they had only a few data, they could probably not clearly distinguish between the different contributions to the measured relaxation process.
\end{abstract}

The kinetics of fast proton transfer has been extensively studied following the introduction of relaxation kinetic methods. ${ }^{1}$ Eigen and co-workers have established that intermolecular protontransfer reactions from and to nitrogen or oxygen atoms in aqueous solution are diffusion-controlled. ${ }^{2}$ Exceptions occur if one reactant is hindered sterically, if the proton to be transferred is hydrogen-bonded, or if a charge is delocalized and the proton-transfer reaction changes that charge, thereby causing a reorganization of the hydrate shell.

In dibasic acids, an intramolecular proton transfer may take place in addition to intermolecular reactions. Schuster et al. ${ }^{3,4}$ have investigated the kinetics of proton-transfer reactions in aqueous solutions of 3-hydroxypyridine (3HP) with ultrasound and temperature jump experiments. Figure 1 shows the mechanism for this compound, which serves as a general model of a dibasic acid. Their studies yielded essentially a single relaxation time, which was assigned to the equilibration between neutral form $A_{N}$ and zwitterion $A_{Z}$. According to their interpretation, three pathways may possibly contribute to this overall reaction: intramolecular proton transfer, proton and hydroxide ion catalyzed pathways via the anion or the cation, and bimolecular reactions involving two $3 \mathrm{HP}$ species. They found no evidence for an intramolecular proton transfer $\left(k_{23}<2 \times 10^{3}\right)$. The elementary reactions in the other pathways proved to be nearly diffusioncontrolled. The mechanism shown in Figure 1 yields in principle four relaxation times; hence, it seemed of interest to calculate the full relaxation spectrum. We measured, therefore, reaction

(1) Techniques of Chemistry; Bernasconi, C. F., Eds.; Wiley: New York, 1986; Vol. VI, Parts I and II.

(2) Eigen, M. Angew. Chem. 1963, 75, 489-508.

(3) Schuster, P.; Tortschanoff, K.; Winkler, H. Z. Naturforschung 1976, $31 c, 219-224$.

(4) Schuster, P.; Wohlschann, P.; Tortschanoff, K. In Chemical Relaxation in Molecular Biology; Rigler, R., Ed.; Springer Verlag: Berlin, 1977; Pecht I, pp 107-190. volumes and reaction enthalpies for some of the proton-transfer reactions and attempted to simulate the relaxation spectrum for temperature jump and ultrasound experiments.

In aqueous solution, intramolecular proton transfer has been demonstrated only for a few compounds. ${ }^{4,5}$ It is believed that the reorganization of the hydrate shell that follows the proton transfer causes this reaction to be much slower than intermolecular proton-transfer reactions. ${ }^{4}$ It has also been suggested that the functional groups involved in the proton transfer have to be close together. ${ }^{5}$ In order to study the possibility of intramolecular proton transfer in aqueous solution further, we chose anthranilic acid (ANA), which may be described by the same general protontransfer mechanism as $3 \mathrm{HP}$. Because the two functional groups of ANA are directly adjacent to each other, intramolecular proton transfer should be more likely for ANA than for 3HP. White and Slutsky ${ }^{6}$ have studied proton-transfer reactions of ANA in water and methanol and concluded that a measurable intramolecular proton transfer takes place in methanol, but not in water. However, they had only a few data for ANA in water, and we did a more detailed experimental study to decide that question definitely.

\section{3-Hydroxypyridine}

Mechanism of Proton-Transfer Reactions in Aqueous Solution. The complete scheme of proton-transfer reactions of $3 \mathrm{HP}$ or any dibasic acid is shown in Figure 1. There are four forms of $3 \mathrm{HP}$ in aqueous solution: the cation $\mathrm{A}^{+}$, the anion $\mathrm{A}^{-}$, the neutral form $A_{N}$, and the zwitterion $A_{Z}$. Three reaction types can take place: intramolecular proton transfer, protolysis and hydrolysis reactions,

(5) Dubois, J. E.; Dreyfus, M. E. In Protons and Ions Involved in Fast Dynamical Phenomena; Proceedings of the 30th International Meeting of the Soc. de chim. phys. de France; Laszlo, P., Ed.; Elsevier: Amsterdam, 1978; pp 169-190.

(6) White, R. D.; Slutsky, L. J. J. Phys. Chem. 1972, 76, 1327-1333. 


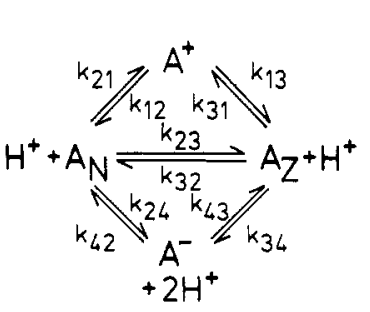

$$
\begin{aligned}
& \begin{array}{c}
2 \mathrm{OH}^{-}+ \\
k_{21}^{\prime} / / \mathrm{k}_{12}^{+} \mathrm{k}_{31}^{+} k_{13}^{\prime}
\end{array} \\
& \underset{\mathrm{k}_{42}}{\left.\mathrm{OH}^{-}+\mathrm{H}_{2} \mathrm{O}\right)} \underset{\mathrm{k}_{24}^{-}}{\mathrm{A}_{43} / \mathrm{k}_{34}^{\prime}} \mathrm{AZ}^{+\mathrm{OH}^{-}} \\
& A_{N}+A^{+} \underset{k_{32}^{+}}{\stackrel{k_{23}^{+}}{\rightleftharpoons}} A_{Z^{+}} A^{+} \\
& A_{N}+A^{-} \underset{k_{32}^{-}}{\stackrel{k_{23}}{\rightleftharpoons}} A_{Z^{+}}+A^{-}
\end{aligned}
$$

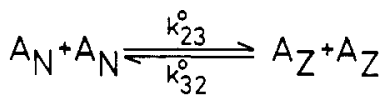

$$
\begin{aligned}
& A^{+}+A^{-} \underset{k_{N N}}{\stackrel{k_{+-}}{\rightleftharpoons}} A_{N^{+}} A_{N} \\
& K_{T}=\frac{A_{Z}}{A_{N}} \\
& K 1=\frac{\left(A_{N}+A_{Z}\right) \cdot H^{+}}{A^{+}} \\
& K 2=\frac{A^{-} \cdot H^{+}}{\left(A_{N}+A_{Z}\right)} \\
& A^{+}+A^{-} \underset{k_{Z Z}}{\stackrel{k_{+-}}{\rightleftharpoons}} A_{Z}+A_{Z} \\
& A^{+}+A^{-} \underset{k_{N Z}}{\stackrel{k_{+-}}{\rightleftharpoons}} A_{N^{+}} A_{Z}
\end{aligned}
$$

Figure 1. Mechanism of proton-transfer reactions of 3-hydroxypyridine in aqueous solution.

and bimolecular reactions among $3 \mathrm{HP}$ species.

Reaction Enthalpies and Reaction Volumes of $3 H P$. The dissociation constants $K_{1}$ and $K_{2}$ of $3 \mathrm{HP}$ and the corresponding reaction enthalpies are available from the literature. ${ }^{7-9}$ However, the two published values for $\Delta H_{1}$ differ substantially (Table III). No reaction volumes for $3 \mathrm{HP}$ seem to be known. $K_{\mathrm{T}}$ has been determined by Metzler et al. ${ }^{7}$ by measuring spectra of the mixture at different temperatures and in different solvents. They assumed that the area of a particular absorption peak is independent of temperature (or solvent or pressure). We denote with $a$ the area of an absorption peak of a given species in the mixture and with $a_{0}$ the area of that absorption peak at a concentration equal to the total concentration of $A_{N}$ and $A_{Z}$. The isomerization constant calculates as

$$
K_{\mathrm{T}}=\left[\mathrm{A}_{\mathrm{N}}\right] /\left[\mathrm{A}_{\mathrm{Z}}\right]=\left(a_{\mathrm{N}} a_{0 \mathrm{Z}}\right) /\left(a_{\mathrm{Z}} a_{\mathrm{ON}}\right)
$$

The areas of the absorption peaks of the individual species $A_{N}$ and $A_{Z}, a_{0 N}$ and $a_{0 Z}$, are difficult to obtain. However, the following condition holds for the area difference $\Delta a$ of absorption peaks at different temperatures:

$$
-\Delta a_{\mathrm{N}} / \Delta a_{\mathrm{Z}}=a_{0 \mathrm{~N}} / a_{0 \mathrm{Z}}
$$

We then obtain for $K_{\mathrm{T}}$

$$
K_{\mathrm{T}}=\left[\mathrm{A}_{\mathrm{N}}\right] /\left[\mathrm{A}_{\mathrm{Z}}\right]=-\left(a_{\mathrm{N}} \Delta a_{\mathrm{Z}}\right) /\left(a_{\mathrm{Z}} \Delta a_{\mathrm{N}}\right)
$$

By fitting log normal curves to the peaks of their spectra, Metzler et al. could separate partially overlapping absorption peaks and determined $K_{\mathrm{T}}$ to be 1.05 at an ionic strength of 0.2 . We repeated their experiment to estimate all three reaction enthalpies. For several temperatures, we determined $K_{1}, K_{2}$, and the spectrum of the overall uncharged form. After correcting for the volume expansion, we calculated the area of the absorption peaks of $A_{N}$ and $A_{Z}$ for each temperature as described by Metzler et al.

For each set of equilibrium values at different temperatures, we then fitted the free energy $\Delta G(T)=-R T \ln K(T)$ to a polynomial of second order in the absolute temperature, $\Delta G(T)=c_{0}$

(7) Metzler, D. E.; Harris, C. M.; Johnson, R. J.; Sianao, D. B.; Thomson, J. A. Biochemistry 1973, 12, 5377-5392.

(8) Christensen, J. J.; Smith, D. E.; Slade, M. D.; Izatt, R. M. Thermochim. Acta 1972, 5, 35-39.

(9) Lezina, V. P.; Shirokova, L. V.; Borunov, M. H.; Stepanyants, A. U.; Smirnov, L. D. Izv. Akad. Nauk SSSR, Ser. Khim. 1981, 4, 753-758.
TABLE I: Absorption Peak Areas and Calculated Thermodynamic Data of 3-Hydroxypyridine

\begin{tabular}{cccccc}
\hline$T,{ }^{\circ} \mathrm{C}$ & $a_{\mathrm{AZ}}$ & $a_{\mathrm{AN}}$ & $K_{\mathrm{T}}$ & $K_{1}$ & $K_{2}$ \\
\hline 56.6 & 26.50 & 23.08 & 0.65 & $1.70 \times 10^{-5}$ & $5.78 \times 10^{-10}$ \\
47.7 & 29.05 & 21.57 & 0.76 & $1.44 \times 10^{-5}$ & $4.71 \times 10^{-10}$ \\
39.2 & 31.66 & 20.22 & 0.89 & $1.22 \times 10^{-5}$ & $3.72 \times 10^{-10}$ \\
31.1 & 34.16 & 18.85 & 1.02 & $1.04 \times 10^{-5}$ & $2.88 \times 10^{-10}$ \\
24.5 & 35.93 & 17.35 & 1.17 & $0.90 \times 10^{-5}$ & $2.26 \times 10^{-10}$ \\
18.2 & 37.72 & 16.17 & 1.32 & $0.79 \times 10^{-5}$ & $1.70 \times 10^{-10}$ \\
13.1 & 39.45 & 15.40 & 1.45 & $0.71 \times 10^{-5}$ & $1.34 \times 10^{-10}$ \\
6.6 & 41.50 & 14.60 & 1.61 & $0.62 \times 10^{-5}$ & $0.96 \times 10^{-10}$ \\
$\Delta G_{\mathrm{T}}=-R T \ln K_{\mathrm{T}}=-578 \pm 2660-(42.95 \pm 17.6) T+$ \\
$(0.1465 \pm 0.029) T^{2}$ \\
$\Delta G_{1}=-R T \ln K_{1}=7740 \pm 2070 \pm(95.62 \pm 13.4) T-$ \\
$(0.0843 \pm 0.024) T^{2}$ \\
$\Delta G_{2}=-R T \ln K_{2}=82400 \pm 2470-(288.20 \pm 16.1) T+$ \\
$(0.5945 \pm 0.027) T^{2}$
\end{tabular}

$+c_{1} T+c_{2} T^{2}$. From the coefficients of the polynomial we calculated $^{10} \Delta H=c_{0}-c_{2} T^{2} ; C_{p}$ may be estimated as $C_{p}=-2 c_{2} \mathrm{~T}$. In Table I we show the obtained equilibrium constants at different temperatures and the polynomials fitted to these data. Some of the calculated standard deviations are quite large. The fitted parameters are not independent of each other; i.e., if we change the constant term in the polynomial, the quadratic term changes accordingly, still yielding a reasonable fit. The calculated value for $\Delta H$ changes very little, however. In a different set of fits, we set the term $c_{0}$ to a value different by the standard deviation from the value of $c_{0}$ obtained in the first fit and allowed only $c_{1}$ and $c_{2}$ to vary (not shown). In the most extreme case, i.e., $K_{1}$, we found a difference of $2 \%$ in the reaction enthalpy although the change in the constant term was about $25 \%$. To get better estimates of the standard deviations of the reaction enthalpies, we redid the fits with $c_{0}$ taken constant at precisely the value shown in Table I. The resulting relative standard deviation of $c_{2}$ was about $1.3 \%$ in the case of $K_{1}$ and smaller than $1 \%$ in the other two cases. The standard deviations shown in Table I reflect the covariance of the parameters rather than the statistical uncertainty of the data. Even with the fits in Table I, we found the relative standard deviations of the equilibrium constants to be smaller than $1 \%$. However, if $C_{p}$ is estimated from $c_{2}$, the standard deviation of $c_{2}$ given in Table I should be used.

In Table III we compare our results with published data. We determined the reaction enthalpy of the first dissociation step, $\Delta H_{1}$, to be $15.2 \mathrm{~kJ} / \mathrm{mol}$. One literature value, i.e., $16.8 \mathrm{~kJ} / \mathrm{mol},{ }^{8}$ was calorimetrically determined and is presumably more reliable than our value. Lezina et al. found $\Delta H_{1}=7.14 \mathrm{~kJ} / \mathrm{mol}$ with ${ }^{1} \mathrm{H}$ NMR measurements. ${ }^{9}$ The reason for this discrepancy is not clear to us. There is a similar discrepancy between our value for the reaction enthalpy of the second dissociation step, $\Delta \mathrm{H}_{2}$, and the value given by Lezina et al. (Table III). However, our results for the tautomeric equilibrium are in sufficient agreement with the results of Metzler et al.

To estimate the reaction volumes, we again used the method of Metzler et al. outlined above, but used absorptions at single wavelengths instead of peak areas. The method can still be used as long as the absorptions of the neutral form and zwitterion are sufficiently different. We assumed that the absorption is independent of pressure. This assumption is probably valid as checked with the absorption of the cation at a higher $\mathrm{pH}$. (We do not show spectra, since Metzler et al. ${ }^{7}$ described the spectra of all ion forms of $3 \mathrm{HP}$ in detail; in addition, our spectra are published elsewhere. ${ }^{11}$ ) Since we used published reaction volumes to calculate the $\mathrm{pH}$ variation of the buffers with pressure, we estimated the reaction volumes of $3 \mathrm{HP}$ in the same manner; i.e., we used the formula $K(p)=K(1 \mathrm{bar}) \exp (-\Delta V / R T \Delta P)$ for the fit, where $R$ is the gas constant and $T$ is the absolute temperature. For $K_{1}$ and $K_{2}$ at $25^{\circ} \mathrm{C}$ we used the values obtained by us, vide supra, and for $K_{\mathrm{T}}$ we chose Metzler's value of 1.05. In Table II, we list

(10) Waelbroeck, M.; Van Obberghen, E.; De Meyts, P. J. Biol. Chem. $1979,254,7736-7740$.

(11) Reiter, J. Dissertation, University of Vienna, 1983. 
TABLE II: Extinctions of 3-Hydroxypyridine Solutions at Different Pressures $^{a}$



${ }^{a} \mathrm{Ph}=$ phosphate buffer; $\mathrm{Cc}=$ cacodylate buffer; $\mathrm{Ac}=$ acetate buffer; $\operatorname{Tr}=$ Tris buffer; $A m=$ ammonia buffer. Reaction volumes were calculated separately for each experiment. The average values are $\Delta V_{\mathrm{T}}=-6.4 \pm 0.6 \mathrm{~mL} / \mathrm{mol}, \Delta V_{1}=-2.5 \pm 0.4 \mathrm{~mL} / \mathrm{mol}$, and $\Delta V_{2}=$ $-10 \pm 3 \mathrm{~mL} / \mathrm{mol}$.

the uncorrected extinctions together with the obtained reaction volumes. The reaction volumes have been determined separately for each experiment because the width of the cell changed slightly between experiments and also during experiments. There are no published reaction volumes for $3 \mathrm{HP}$ with which we could compare our estimations. Generally, the reaction volume of a reaction in which the total number of charges increases by two is about -10 to $-20 \mathrm{~mL} / \mathrm{mol}^{12}$ The dissociation reaction of phenol has a volume change of $-18.7 \mathrm{~mL} / \mathrm{mol} .^{12}$ The proton dissociation of the pyridinium cation, where the number of charges is constant, has a reaction volume of $9.8 \mathrm{~mL} / \mathrm{mol}^{12}$ These reaction volumes

(12) Asano, T.; Le Noble, W. J. Chem. Rev. 1978, 78, 407-489.
TABLE III: Thermodynamic Data of 3-Hydroxypyridine

\begin{tabular}{cccc}
\hline reaction & $\mathrm{pK}$ & $\Delta H$, & $\Delta V$, \\
or $K$ & $\mathrm{~kJ} / \mathrm{mol}$ & $\mathrm{mL} / \mathrm{mol}$ \\
\hline$\left[\mathrm{A}^{+}\right]=K_{\mathrm{T}} /\left(1+K_{\mathrm{T}}\right)\left[\mathrm{A}_{\mathrm{Z}}\right]+$ & $\mathrm{p} K_{1}=$ & 15.2 & -2.5 \\
$1 /\left(1+K_{\mathrm{T}}\right)\left[\mathrm{A}_{\mathrm{N}}\right]+\left[\mathrm{H}^{+}\right]$ & 5.04 & \multicolumn{2}{c}{} \\
& $4.91^{a}$ & $16.8^{b}$ & \\
& \multicolumn{4}{c}{$7.41^{c}$} \\
$K_{\mathrm{T}} /\left(1+K_{\mathrm{T}}\right)\left[\mathrm{A}_{\mathrm{Z}}\right]+1 /(1+$ & $\mathrm{p} K_{2}=$ & 29.6 & -7 to -15 \\
$\left.K_{\mathrm{T}}\right)\left[\mathrm{A}_{\mathrm{N}}\right]=\left[\mathrm{A}^{-}\right]+\left[\mathrm{H}^{+}\right]$ & 8.64 & & \\
& $8.62^{a}$ & $19.8^{c}$ & \\
$\mathrm{~A}_{\mathrm{N}}=\mathrm{A}_{\mathrm{Z}}$ & $K_{\mathrm{T}}=$ & -13.6 & -6.4 (spectr) \\
& 1.16 & & \\
& $1.05^{a}$ & $-13.0^{a}$ & -8.1 (ultrasound)
\end{tabular}

${ }^{a}$ Reference 7. ${ }^{b}$ Reference $8 .{ }^{c}$ Reference 9.

may be compared to our results in Table II and Table III. We have also calculated $\Delta V_{\mathrm{T}}$ from the amplitudes of the ultrasound experiments done by Schuster et al. ${ }^{3}$ and have obtained $\Delta V_{\mathrm{T}}=$ $-8.1 \mathrm{~mL} / \mathrm{mol}$, using $\Delta H_{\mathrm{T}}=-13.6 \mathrm{~kJ} / \mathrm{mol}$. Strictly, the amplitude of the ultrasound absorption furnishes the absolute value of the reaction volume at constant entropy, but it seems reasonable to assume a negative sign.

Relaxation Spectrum of a Dibasic Acid. The kinetic scheme of proton-transfer reactions of a dibasic acid in aqueous solution consists, at least in principle, of 16 individual reactions (Figure 1). However, near equilibrium, where the kinetic equations can be linearized, ${ }^{13}$ it can be described by four independent normal reactions. With the thermodynamic parameters given in the last section and with published kinetic parameters, ${ }^{3}$ we are able to simulate the relaxation spectrum for $3 \mathrm{HP}$. The results should apply for any dibasic acid with a $K_{\mathrm{T}}$ near unity and an isoelectric point near $\mathrm{pH} 7$. Even if these conditions are not met, some of the relaxation modes described here will still be the same. We thus describe first the relaxation spectrum of a general dibasic acid, using $3 \mathrm{HP}$ as an example. Subsequently, we shall discuss the simulation of $3 \mathrm{HP}$ more specifically.

We denote overall reactions with the equal sign $(=)$ and use two reverse double half-arrows $(\rightleftharpoons)$ for individual reaction steps. In formulas for amplitudes and inverse relaxation times, the equilibrium concentration of a given species is denoted by its symbol in brackets, i.e., $\left[\mathrm{A}^{+}\right]$or $\left[\mathrm{OH}^{-}\right]$. Some normal reactions and corresponding formulas have fractional stoichiometric coefficients, which we always denote by $x$ and $y$ to save on symbols. These coefficients are different in different equations.

Near chemical equilibrium, the kinetics of a dibasic acid with a proton-transfer mechanism as shown in Figure 1 and kinetic constants similar to that of $3 \mathrm{HP}$ can be described by the following four normal reactions:

I. Normal Reaction $A_{\mathrm{N}}=A_{\mathrm{Z}}$. The condition $\Delta\left[\mathrm{A}_{\mathrm{N}}\right]=\Delta\left[\mathrm{A}_{\mathrm{Z}}\right]$ and the steady-state conditions $\Delta\left[\mathrm{A}^{+}\right]=\Delta\left[\mathrm{H}^{+}\right]=0$ are used to calculate the approximate inverse relaxation time. Three pathways contribute to the equilibrium between the neutral form and the zwitterion. $^{3-5}$

Ia. Intramolecular Proton-Transfer Reaction $A_{\mathrm{N}} \rightleftharpoons A_{\mathrm{Z}}$. The intramolecular reaction path is independent of $\mathrm{pH}$ and independent of the concentration of the dibasic acid. For $3 \mathrm{HP}$, it is not important. The contribution to the inverse relaxation time is

$$
(1 / \tau)_{\mathrm{Ia}}=k_{23}+k_{32}
$$

Ib. Dissociative Reaction Paths.

$$
\begin{aligned}
& \mathrm{A}_{\mathrm{N}}+\mathrm{H}^{+} \rightleftharpoons \mathrm{A}^{+}, \mathrm{A}^{+} \rightleftharpoons \mathrm{A}_{\mathrm{Z}}+\mathrm{H}^{+} ; \Delta\left[\mathrm{A}^{+}\right]=0 \\
& \mathrm{~A}_{\mathrm{N}} \rightleftharpoons \mathrm{A}^{-}+\mathrm{H}^{+}, \mathrm{A}^{-}+\mathrm{H}^{+} \rightleftharpoons \mathrm{A}_{\mathrm{Z}} ; \Delta\left[\mathrm{A}^{-}\right]=0
\end{aligned}
$$

$\mathrm{A}_{\mathrm{N}}+\mathrm{H}_{2} \mathrm{O} \rightleftharpoons \mathrm{A}^{+}+\mathrm{OH}^{-}, \mathrm{A}^{+}+\mathrm{OH}^{-} \rightleftharpoons \mathrm{A}_{\mathrm{Z}}+\mathrm{H}_{2} \mathrm{O}$ $\Delta\left[\mathrm{A}^{+}\right]=0$

$\mathrm{A}_{\mathrm{N}}+\mathrm{OH}^{-} \rightleftharpoons \mathrm{A}^{-}+\mathrm{H}_{2} \mathrm{O}, \mathrm{A}^{-}+\mathrm{H}_{2} \mathrm{O} \rightleftharpoons \mathrm{A}_{\mathrm{Z}}+\mathrm{OH}^{-}$ $\Delta\left[\mathrm{A}^{-}\right]=0$

(13) Eigen, M.; De Maeyer, L. In Techniques of Chemistry, Hammes, G. G., Ed.; Wiley: New York, 1974; Vol. VI, Part II; pp 63-146. 
These pathways depend on $\mathrm{pH}$ but do not depend on the concentration of the dibasic acid. The contribution to the inverse relaxation time calculates as

$$
\begin{gathered}
(1 / \tau)_{1 \mathrm{~b}}=\left[\mathrm{H}^{+}\right]\left(k_{21} k_{13}+k_{31} k_{12}\right) /\left(k_{12}+k_{13}\right)+\left(k_{24} k_{43}+\right. \\
\left.k_{34} k_{42}\right) /\left(k_{42}+k_{43}\right)+\left[\mathrm{H}_{2} \mathrm{O}\right]\left(k_{21}^{\prime} k_{13}^{\prime}+k_{31}^{\prime} k_{12}^{\prime}\right) /\left(k_{12}^{\prime}+\right. \\
\left.k_{13}^{\prime}\right)+\left[\mathrm{OH}^{-}\right]\left(k_{24}^{\prime} k_{43}^{\prime}+k_{34}^{\prime} k_{42}^{\prime}\right) /\left(k_{42}^{\prime}+k_{43}^{\prime}\right)
\end{gathered}
$$

This expression is computed by using the steady-state approximations for hydrolysis reactions and for protolysis reactions separately. Schuster et al..$^{3}$ have applied the steady-state approximation for the cation and anion by using the protolysis and hydrolysis reactions together; i.e., they assumed that these reactions are coupled via the water dissociation reaction. In the reactions written above one would have to combine hydrolysis reactions with protolysis reactions and the water dissociation reaction. They obtained for the pathway over the cation

$$
\begin{aligned}
& (1 / \tau)_{\mathrm{Ib}, \mathrm{A}^{+}}=\left[\left(k_{21}\left[\mathrm{H}^{+}\right]+k^{\prime}{ }_{21}\left[\mathrm{H}_{2} \mathrm{O}\right]\right) \times\right. \\
& \left(k_{13}+k_{13}^{\prime}\left[\mathrm{OH}^{-}\right]\right)+\left(k_{31}\left[\mathrm{H}^{+}\right]+k_{31}^{\prime}\left[\mathrm{H}_{2} \mathrm{O}\right]\right)\left(k_{12}+\right. \\
& \left.\left.k_{12}^{\prime}\left[\mathrm{OH}^{-}\right]\right)\right] /\left(k_{12}+k_{12}^{\prime}\left[\mathrm{OH}^{-}\right]+k_{13}+k_{13}^{\prime}\left[\mathrm{OH}^{-}\right]\right)
\end{aligned}
$$

which should be compared to the first and the third term in the equation given just before. They also derived an analogous expression for the pathway over the anion. The first approximation given above is valid if the water dissociation reaction is slow compared to the protolysis and hydrolysis reactions of the dibasic acid. $^{5}$ This assumption is, with diffusion-controlled rate constants, usually fulfilled if the concentration of the dibasic acid is larger than a certain threshold; this threshold can easily be calculated for a given system, being about $10^{-4} \mathrm{~mol} / \mathrm{L}$ for $3 \mathrm{HP}$ at $\mathrm{pH} 7$. At lower concentrations of the dibasic acid, the rate of the dissociation reaction of water is faster than the rate of the protolysis and hydrolysis reactions of the dibasic acid; then, the second approximation furnishes better results. Of course, there is also a concentration range where neither approximation is strictly valid. In the case of 3HP, the numerical differences between the two approximations are negligible. We simulated several dibasic acids and found that in most cases with a significant difference between the two approximations, i.e., a difference larger than experimental error, mode $I$ is not just the reaction $A_{N}=A_{z}$, but also comprises other reactions. In such cases, one has to carefully check the validity of the steady-state assumption. ${ }^{14}$ With Castellan's method the appropriate approximation often can be seen more easily. ${ }^{15}$ In practice it is probably sufficient to use the slow water dissociation approximation; it yields a simpler expression and is valid in the concentration range ordinarily used; i.e., $c_{3 \mathrm{HP}}>10^{-4} \mathrm{~mol} / \mathrm{L}$. However, the approximation should always be compared with the numerical value of the inverse relaxation time calculated from the complete kinetic system.

In order to obtain a simple expression, we assume protolysis diffusion-controlled reactions to have the same rate constant $k_{\mathrm{H}}$ and hydrolysis diffusion-controlled reactions to have the same rate constant $k_{\mathrm{OH}}$. With the slow water dissociation approximation, we then obtain

$$
\begin{aligned}
(1 / \tau)_{\text {diss }}=k_{\mathrm{H}}\left[\mathrm{H}^{+}\right]+k_{\mathrm{OH}}\left[\mathrm{OH}^{-}\right]+ & 0.5\left(k_{\mathrm{OH}} K_{\mathrm{W}} / K_{1}+k_{\mathrm{H}} K_{2}\right)\left(1+K_{\mathrm{T}}\right)^{2} / K_{\mathrm{T}}
\end{aligned}
$$

The constant term is about equal to the sum of the reverse reaction rate constants, i.e., to the water catalyzed terms. It is large if $K_{1}$ is small (basic system) or if $K_{2}$ is large (acid system). The constant term is also large if $K_{\mathrm{T}}$ is very small or very large. However, the assumptions made for the steady-state approximation are most likely valiud if $K_{\mathrm{T}}$ is close to unity.

Ic. Bimolecular Reactions. $A_{\mathrm{N}}+A^{+} \rightleftharpoons A_{\mathrm{Z}}+A^{+} ; A_{\mathrm{N}}+A^{-}$ $\rightleftharpoons A_{\mathrm{Z}}+A^{-} ; 2 A_{\mathrm{N}} \rightleftharpoons 2 A_{\mathrm{Z}}$. This contribution to the normal reaction depends on the concentrations of $\mathrm{A}^{+}, \mathrm{A}^{-}, \mathrm{A}_{\mathrm{N}}$ and $\mathrm{A}_{\mathrm{Z}}$. In case of $3 \mathrm{HP}$, the last reaction is much slower than the former two. The contribution to the relaxation time is

(14) Klonowski, W. Biophys. Chem. 1983, 18, 73-87

(15) Castellan, G. W. Ber. Bunsen-Ges. Phys. Chem. 1963, 67, 898-908.

(16) Christensen, J. J.; Hansen, L. D.; Izatt, R. M. Handbook of Proton Ionization Heats; Wiley: New York, 1976.

$$
\begin{array}{r}
(1 / \tau)_{\mathrm{Ic}}=k^{+}{ }_{23}\left[A^{+}\right]+k^{+}{ }_{32}\left[\mathrm{~A}^{+}\right]+k^{-}{ }_{23}\left[\mathrm{~A}^{-}\right]+k^{-}{ }_{32}\left[\mathrm{~A}^{-}\right]+ \\
4 k^{\circ}{ }_{23}\left[\mathrm{~A}_{\mathrm{N}}\right]+4 k^{\circ}{ }_{32}\left[\mathrm{~A}_{\mathrm{Z}}\right]
\end{array}
$$

Id. The $\mathrm{I}$ factor of the amplitude of mode $\mathrm{I}$ calculates as

$$
\begin{aligned}
& \Gamma=\left[\mathrm{A}_{\mathrm{N}}\right]\left[\mathrm{A}_{\mathrm{Z}}\right] /\left(\left[\mathrm{A}_{\mathrm{N}}\right]+\left[\mathrm{A}_{\mathrm{Z}}\right]\right)= \\
& c_{0}\left[\left(K_{\mathrm{T}} /\left(1+K_{\mathrm{T}}\right)^{2}\right) /\left(1+\left[\mathrm{H}^{+}\right] / K_{1}+K_{2} /\left[\mathrm{H}^{+}\right]\right)\right]
\end{aligned}
$$

where $c_{0}$ is the total concentration of 3HP. The amplitude reaches its maximum at the isoelectric point and at $K_{\mathrm{T}}=1$. If $K_{\mathrm{T}}$ is very different from unity, the amplitude of mode $I$ is small.

II. Normal Reaction $A^{+}+A^{-}=x A_{\mathrm{N}}+(2-x) A_{\mathrm{z}}, 0 \leq x \leq$ 2. To calculate the inverse relaxation time of the normal mode II, we use the conditions $\Delta\left[\mathrm{H}^{+}\right]=0$ and $\Delta\left[\mathrm{A}^{+}\right]=\Delta\left[\mathrm{A}^{-}\right]$and assume that $A_{N}$ and $A_{Z}$ participate in the normal mode like the fraction of their rates of production or disappearance; i.e., (2 x) $\Delta\left[\mathrm{A}_{\mathrm{N}}\right]=x \Delta\left[\mathrm{A}_{\mathrm{Z}}\right]$, where $x / 2$ calculates as the fraction of the equilibrium rates producing $A_{N}$ divided by the sum of equilibrium rates producing $A_{N}$ and $A_{Z}$; see sections IIb and IIIc, where we wrote such fractions explicitly. For 3HP both fractions are approximately equal; i.e., $x$ is near unity. If $x$ and $2-x$ are very different from each other, the faster reactions are often decoupled from the slower reactions. In such a case, the stated assumptions for either the first mode or the second mode may no longer be valid.

Normal reactions have been compared to normal vibrations, which are obtained by a similar mathematical formalism. This "symmetric" mode seems particularly suitable for such a comparison. Two pathways contribute to mode II:

IIa. Dissociative Reaction Paths.

$$
\begin{gathered}
\mathrm{A}^{+} \rightleftharpoons \mathrm{H}^{+}+\mathrm{A}_{\mathrm{N}}\left(\mathrm{A}_{\mathrm{Z}}\right), \mathrm{A}^{-}+\mathrm{H}^{+} \rightleftharpoons \mathrm{A}_{\mathrm{N}}\left(\mathrm{A}_{\mathrm{Z}}\right) ; \Delta\left[\mathrm{H}^{+}\right]=0 \\
\mathrm{~A}^{+}+\mathrm{OH}^{-} \rightleftharpoons \mathrm{A}_{\mathrm{N}}\left(\mathrm{A}_{\mathrm{Z}}\right)+\mathrm{H}_{2} \mathrm{O}, \mathrm{A}^{-}+\mathrm{H}_{2} \mathrm{O}= \\
\mathrm{A}_{\mathrm{N}}\left(\mathrm{A}_{\mathrm{Z}}\right)+\mathrm{OH}^{-} ; \Delta\left[\mathrm{OH}^{-}\right]=0
\end{gathered}
$$

The inverse relaxation time depends on $\mathrm{pH}$, but is independent of the concentration of the dibasic acid. The contribution to the approximate inverse relaxation time calculates as

$$
\begin{array}{r}
(1 / \tau)_{\mathrm{IIa}}=\left(( k _ { 1 2 } k _ { 4 2 } + k _ { 1 3 } k _ { 4 3 } + k _ { 1 2 } k _ { 4 3 } + k _ { 1 3 } k _ { 4 2 } ) \left(\left[\mathrm{A}^{-}\right]+\right.\right. \\
\left.\left[\mathrm{A}^{+}\right]\right)+4 k_{21} k_{24} x\left[\mathrm{~A}_{\mathrm{N}}\right]+4 k_{31} k_{34} y\left[\mathrm{~A}_{\mathrm{Z}}\right]+2\left(k_{21} k_{34}+\right. \\
\left.\left.k_{31} k_{24}\right)\left(y\left[\mathrm{~A}_{\mathrm{N}}\right]+x\left[\mathrm{~A}_{\mathrm{Z}}\right]\right)\right) /\left(k_{21}\left[\mathrm{~A}_{\mathrm{N}}\right]+k_{31}\left[\mathrm{~A}_{\mathrm{Z}}\right]+k_{42}\left[\mathrm{~A}^{-}\right]+\right. \\
\left.k_{43}\left[\mathrm{~A}^{-}\right]\right)+\left(( k _ { 1 2 } ^ { \prime } k _ { 4 2 } ^ { \prime } + k _ { 1 3 } ^ { \prime } k _ { 4 3 } ^ { \prime } + k _ { 1 2 } ^ { \prime } k _ { 4 3 } ^ { \prime } + k _ { 1 3 } ^ { \prime } k _ { 4 2 } ^ { \prime } ) \left(\left[\mathrm{A}^{-}\right]+\right.\right. \\
\left.\left[\mathrm{A}^{+}\right]\right)+4 k_{21}^{\prime} k_{24}^{\prime} x\left[\mathrm{~A}_{\mathrm{N}}\right]+4 k_{31}^{\prime} k_{34}^{\prime} y\left[\mathrm{~A}_{\mathrm{Z}}\right]+2\left(k_{21}^{\prime} k_{34}^{\prime}+\right. \\
\left.k^{\prime}{ }_{31}^{\prime} k_{24}^{\prime}\right)\left[\mathrm{H}_{2} \mathrm{O}\right]\left(y\left[\mathrm{~A}_{\mathrm{N}}\right]+x\left[\mathrm{~A}_{\mathrm{Z}}\right)\right) /\left(k_{12}^{\prime}\left[\mathrm{A}^{+}\right]+k_{13}^{\prime}\left[\mathrm{A}^{+}\right]+\right. \\
\left.k_{24}^{\prime}\left[\mathrm{A}_{\mathrm{N}}\right]+k_{34}^{\prime}\left[\mathrm{A}_{\mathrm{Z}}\right]\right)
\end{array}
$$

where the coefficients $x$ and $y$ sum to unity and slow water dissociation is assumed. We ignore this time the case of fast water dissociation. If we assume all diffusion-controlled constants of protolysis reactions to take on the value $k_{\mathrm{H}}$ and assume all diffusion-controlled constants of hydrolysis reactions to take on the value $k_{\mathrm{OH}}$ and assume additionally that $x=y$ holds, we obtain

$$
\begin{aligned}
&(1 / \tau)_{\mathrm{IIa}}=\left(2 k_{\mathrm{H}} K_{1}\left(\left[\mathrm{~A}^{+}\right]+\left[\mathrm{A}^{-}\right]\right)+\left(1+K_{\mathrm{T}}\right) k_{\mathrm{H}} K_{2}\left[\mathrm{~A}_{\mathrm{N}}\right] \times\right. \\
&\left.\left(4+\left(1+K_{\mathrm{T}}\right)^{2} / K_{\mathrm{T}}\right)\right) /\left(\left[\mathrm{A}_{\mathrm{N}}\right]\left(1+K_{\mathrm{T}}\right)+2\left[\mathrm{~A}^{-}\right]\right)+ \\
&\left(2 k_{\mathrm{OH}}\left(K_{\mathrm{W}} / K_{2}\right)\left(\left[\mathrm{A}^{+}\right]+\left[\mathrm{A}^{-}\right]\right)+\left(1+K_{\mathrm{T}}\right) k_{\mathrm{OH}}\left(K_{\mathrm{W}} / K_{1}\right) \times\right. \\
& {\left.\left[\mathrm{A}_{\mathrm{N}}\right]\left(4+\left(1+K_{\mathrm{T}}\right)^{2} / K_{\mathrm{T}}\right)\right) /\left(\left[\mathrm{A}_{\mathrm{N}}\right]\left(1+K_{\mathrm{T}}\right)+2\left[\mathrm{~A}^{+}\right]\right) }
\end{aligned}
$$

where $K_{\mathrm{W}}$ is the ionization product of water. Each denominator consists of a constant term and a $\mathrm{pH}$-dependent term. The $\mathrm{pH}$ dependent part assumes its minimum at the isoelectric point, $\mathrm{p} K_{1}$, and it is logarithmically symmetric, i.e., symmetric as a function of $\mathrm{pH}-\mathrm{p} K_{1}$. To see this more clearly, we substitute for the equilibrium concentrations and rearrange as follows:

$$
\begin{gathered}
(1 / \tau)_{\mathrm{IIa}}=k_{\mathrm{H}}\left(2\left(\left[\mathrm{H}^{+}\right]+K_{1} K_{2} /\left[\mathrm{H}^{+}\right]\right)+K_{2}(4+(1+\right. \\
\left.\left.\left.K_{\mathrm{T}}\right)^{2} / K_{\mathrm{T}}\right)\right) /\left(1+2 K_{2} /\left[\mathrm{H}^{+}\right]\right)+ \\
k_{\mathrm{OH}}\left(2\left(\left[\mathrm{OH}^{-}\right]+K_{\mathrm{W}^{2}} /\left(K_{1} K_{2}\left[\mathrm{OH}^{-}\right]\right)\right)+\left(K_{\mathrm{W}} / K_{1}\right)(4+(1+\right. \\
\left.\left.\left.K_{\mathrm{T}}\right)^{2} / K_{\mathrm{T}}\right)\right) /\left(1+2 K_{\mathrm{W}} /\left(K_{1}\left[\mathrm{OH}^{-}\right]\right)\right)
\end{gathered}
$$

After substituting additionally $T_{\mathrm{H}}=\left[\mathrm{H}^{+}\right] /\left(K_{1} K_{2}\right)^{1 / 2}, T k_{\mathrm{H}}=$ 


$$
\begin{gathered}
k_{\mathrm{H}}\left(K_{1}\right)^{1 / 2}\left(K_{2}\right)^{1 / 2}, T k_{\mathrm{OH}}=k_{\mathrm{OH}} K_{\mathrm{W}} /\left(K_{1} K_{2}\right)^{1 / 2}, T_{\mathrm{OH}}=1 / T_{\mathrm{H}} \text {, and } \\
T K_{2}=\left(K_{2} / K_{1}\right)^{1 / 2}, \text { we obtain } \\
(1 / \tau)_{\mathrm{Ila}}=T k_{\mathrm{H}}\left(2\left(T_{\mathrm{H}}+T_{\mathrm{OH}}\right)+T K_{2}(4+(1+\right. \\
\left.\left.\left.K_{\mathrm{T}}\right)^{2} / K_{\mathrm{T}}\right)\right) /\left(1+2 T K_{2} / T_{\mathrm{H}}\right)+T k_{\mathrm{OH}}\left(2\left(T_{\mathrm{OH}}+T_{\mathrm{H}}\right)\right)+ \\
\left.T K_{2}\left(4+\left(1+K_{\mathrm{T}}\right)^{2} / K_{\mathrm{T}}\right)\right) /\left(1+2 T K_{2} / T_{\mathrm{OH}}\right)
\end{gathered}
$$

The denominators are similar to the expression $(1 / \tau)_{\mathrm{Ia}}$, except that each of the denominators of $(1 / \tau)_{\mathrm{II}}$ assumes its minimum at the isoelectric point, where $T_{\mathrm{H}}$ equals unity. The nominators depend on $T_{\mathrm{H}}$ as well; they change in the form of a titration curve in the vicinity of $T K_{1}=1 / T K_{2}$ and $T K_{2}$.

If the regarded system is neutral, i.e., $\mathrm{p} K_{\mathrm{I}}=7$, which is almost the case with $3 \mathrm{HP}$, then $(1 / \tau)_{\mathrm{IIa}}$ as a function of $\mathrm{pH}$ is very similar to $(1 / \tau)_{\mathrm{Ib}}$, except that the former is modified by a $\mathrm{pH}$-dependent nominator. If, in such a case, $(1 / \tau)_{\text {IIa }}$ were to be modeled with a function like $(1 / \tau)_{\mathrm{Ib}}$, this could lead to the determination of an incorrect constant term.

IIb. Bimolecular Reactions $A^{+}+A^{-} \rightleftharpoons 2 A_{\mathrm{Z}}, A^{+}+A^{-} \rightleftharpoons 2 A_{\mathrm{N}}$, $A^{+}+A^{-} \rightleftharpoons A_{\mathrm{Z}}+A_{\mathrm{N}}$. This reaction path depends on the concentrations of $\mathrm{A}^{+}, \mathrm{A}^{-}, \mathrm{A}_{\mathrm{N}}$, and $\mathrm{A}_{\mathrm{Z}}$. Note that the three reactions contribute also to the pathway Ic, which is seen by applying a steady-state assumption to the cation and anion. This contribution, however, may be absorbed in the reaction $2 \mathrm{~A}_{\mathrm{N}} \rightleftharpoons 2 \mathrm{~A}_{\mathrm{Z}}$. We use the symbols $\mathrm{NN}, \mathrm{NZ}$, and $\mathrm{ZZ}$ to identify the three forward rate constants-in contrast to the nomenclature in Figure 1. The contribution to the approximate inverse relaxation time calculates as

$$
\begin{array}{r}
(1 / \tau)_{\mathrm{IIb}}=\left(k_{+-\mathrm{NN}}+k_{+-\mathrm{ZZ}}+k_{+-\mathrm{NZ}}\right)\left(\left[\mathrm{A}^{+}\right]+\left[\mathrm{A}^{-}\right]\right)+ \\
4 k_{\mathrm{NN}} x\left[\mathrm{~A}_{\mathrm{N}}\right]+4 k_{\mathrm{ZZ}}(1-x)\left[\mathrm{A}_{\mathrm{Z}}\right]+2 k_{\mathrm{NZ}}(1-x)\left[\mathrm{A}_{\mathrm{N}}\right]+ \\
2 k_{\mathrm{NZ}} x\left[\mathrm{~A}_{\mathrm{Z}}\right]
\end{array}
$$

where the assumption that $A_{N}$ and $A_{Z}$ participate in the normal reaction like the fractions of their rates of production has been used. If we consider only these three reactions, $x$ calculates as

$$
x=\left(2 k_{+-\mathrm{NN}}+k_{+-\mathrm{NZ}}\right) /\left[2.0\left(k_{+-\mathrm{NN}}+k_{+-\mathrm{NZ}}+k_{+-\mathrm{ZZ}}\right)\right]
$$

In general, $x$ has to be calculated by using all reactions of the pathways IIa and IIb.

The rates of the three reactions have not been measured to our knowledge. The sum of all three forward rates should be faster by a factor of approximately 2 than a bimolecular reaction Ic since the cation (anion) can react with both functional groups. In addition, the reactants are differently charged, which should increase the rates of these reactions. For statistical reasons, the second reaction written above should be faster in the forward reaction by a factor of 2 than the other two reactions. In our simulation, however, we have set each of the three forward rate constants to the diffusion-controlled limit of $9 \times 10^{8} \mathrm{~L} \mathrm{~mol}^{-1} \mathrm{~s}^{-1}$.

IIC. The $\Gamma$ factor of the amplitude of mode II calculates as

$$
\Gamma=1 /\left(1 /\left[\mathrm{A}^{+}\right]+1 /\left[\mathrm{A}^{-}\right]+x^{2} /\left[\mathrm{A}_{\mathrm{N}}\right]+(2-x)^{2} /\left[\mathrm{A}_{\mathrm{Z}}\right]\right)
$$

It increases with decreasing difference between the two $\mathrm{p} K$ values of the dibasic acid and assumes its maximum at the isoelectric point. From that maximum the amplitude of this mode usually falls off faster with changing $\mathrm{pH}$ than the amplitude of mode $\mathrm{I}$. This is easily understood since the amplitude depends on the concentrations of both $\mathrm{A}^{+}$and $\mathrm{A}^{-}$. However, if either the condition $K_{\mathrm{T}} \gg\left(K_{1} / K_{2}\right)^{1 / 2}$ or the condition $K_{\mathrm{T}} \ll\left(K_{2} / K_{1}\right)^{1 / 2}$ holds, the concentration of either $A_{N}$ or $A_{Z}$ will be smaller than the concentrations of $\mathrm{A}^{+}$and $\mathrm{A}^{-}$at the isoelectric point. In this case, the $\mathrm{pH}$ profiles of the amplitudes of the modes I and II are similar in the vicinity of the isoelectric point. In addition, at the isoelectric point, the $\Gamma$ factor of mode II will be larger than the $\Gamma$ factor of mode I. For 3HP, the amplitude of mode II is small compared to the amplitude of mode $\mathrm{I}$.

III. IIIa: At $\mathrm{pH} \sim \mathrm{p} K_{1}$

$$
\mathrm{A}^{+}=x \mathrm{~A}_{\mathrm{N}}+(1-x) \mathrm{A}_{\mathrm{Z}}+\mathrm{H}^{+}, 0 \leq x \leq 1 \text {, if } \mathrm{p} K_{1}<7
$$

$\mathrm{A}^{+}+\mathrm{OH}^{-}=$

$$
x \mathrm{~A}_{\mathrm{N}}+(1-x) \mathrm{A}_{\mathrm{Z}}+\mathrm{H}_{2} \mathrm{O}, 0 \leq x \leq 1 \text {, if } \mathrm{p} K_{1}>7
$$

IIIb: At $\mathrm{pH} \sim \mathrm{pK}_{2}$

$$
\begin{gathered}
x \mathrm{~A}_{\mathrm{N}}+(1-x) \mathrm{A}_{\mathrm{Z}}+\mathrm{H}_{2} \mathrm{O}= \\
\mathrm{A}^{-}+\mathrm{OH}^{-}, 0 \leq x \leq 1, \text { if } \mathrm{p} K_{2}>7 \\
x \mathrm{~A}_{\mathrm{N}}+(1-x) \mathrm{A}_{\mathrm{Z}}=\mathrm{A}^{-}+\mathrm{H}^{+}, 0 \leq x \leq 1, \text { if } \mathrm{p} K_{2}<7
\end{gathered}
$$

The fractional coefficients depend on the kinetic constants; see below. They are not equal for the individual overall reactions written above. For $3 \mathrm{HP}, x$ is approximately $1 / 2$ in each case, however. Mode III consists of two branches. For each branch, depending on the equilibrium constant, either protolysis reactions or hydrolysis reactions will dominate. If a $\mathrm{p} K$ value is close to $\mathrm{pH} 7$, the normal reaction might consist of both reaction types. In the case of $3 \mathrm{HP}$, the first branch consists of protolysis reactions and the second branch of hydrolysis reactions.

The relaxation times are straightforward to calculate: with $\Delta\left[\mathrm{A}^{+}\right]=-\Delta\left[\mathrm{H}^{+}\right], \Delta\left[\mathrm{A}^{-}\right]=0$, and $(1-x) \Delta\left[\mathrm{A}_{\mathrm{N}}\right]=x \Delta\left[\mathrm{A}_{\mathrm{Z}}\right]$, we obtain

$$
\begin{aligned}
&(1 / \tau)_{\mathrm{IIIa}}= k_{12}+k_{13}+k_{21}\left(x\left[\mathrm{H}^{+}\right]+\left[\mathrm{A}_{\mathrm{N}}\right]\right)+ \\
& k_{31}\left((1-x)\left[\mathrm{H}^{+}\right]+\left[\mathrm{A}_{\mathrm{Z}}\right]\right), x=k_{12} /\left(k_{12}+k_{13}\right)
\end{aligned}
$$

whereas using $\Delta\left[\mathrm{A}^{+}\right]=-\Delta\left[\mathrm{H}^{+}\right]=0$ and $(1-x) \Delta\left[\mathrm{A}_{\mathrm{N}}\right]=x \Delta\left[\mathrm{A}_{\mathrm{Z}}\right]$ yields

$$
\begin{aligned}
(1 / \tau)_{\mathrm{IIIb}}= & \left(k_{42}+k_{43}\right)\left[\mathrm{H}_{2} \mathrm{O}\right]+k_{24}\left(x\left[\mathrm{OH}^{-}\right]+\left[\mathrm{A}_{\mathrm{N}}\right]\right)+ \\
& k_{34}\left((1-x)\left[\mathrm{OH}^{-}\right]+\left[\mathrm{A}_{\mathrm{Z}}\right]\right), x=k_{42} /\left(k_{42}+k_{43}\right)
\end{aligned}
$$

We assumed slow water dissociation in both cases. If all diffusion-controlled rate constants of protolysis reactions take on the same value $k_{\mathrm{H}}$, the inverse relaxation time $(1 / \tau)_{\mathrm{IIIa}}$ of $3 \mathrm{HP}$ calculates as

$$
(1 / \tau)_{\mathrm{IIIa}}=k_{\mathrm{H}} K_{\mathrm{l}}+k_{\mathrm{H}}\left(\left[\mathrm{H}^{+}\right]+\left[\mathrm{A}_{\mathrm{N}}\right]+\left[\mathrm{A}_{\mathrm{Z}}\right]\right)
$$

Likewise, the inverse relaxation time $(1 / \tau)_{\text {lIIb }}$ for $3 \mathrm{HP}$ is

$$
(1 / \tau)_{\mathrm{IIIb}}=k_{\mathrm{OH}}\left(\left[\mathrm{A}_{\mathrm{N}}\right]+\left[\mathrm{A}_{\mathrm{Z}}\right]+\left[\mathrm{OH}^{-}\right]\right)+k_{\mathrm{OH}} K_{\mathrm{W}} / K_{2}
$$

where all diffusion-controlled rate constants of hydrolysis reactions are assumed to take on the value $k_{\mathrm{OH}}$.

The $\Gamma$ factors for $3 \mathrm{HP}$ calculate as

$$
\begin{gathered}
\Gamma_{\mathrm{IIIa}}=1 /\left(1 /\left[\mathrm{H}^{+}\right]+1 /\left[\mathrm{A}^{+}\right]+x^{2} /\left[\mathrm{A}_{\mathrm{N}}\right]+(1-x)^{2} /\left[\mathrm{A}_{\mathrm{Z}}\right]\right) \\
\Gamma_{\mathrm{IIIb}}=1 /\left(1 /\left[\mathrm{OH}^{-}\right]+1 /\left[\mathrm{H}_{2} \mathrm{O}\right]+1 /\left[\mathrm{A}^{-}\right]+x^{2} /\left[\mathrm{A}_{\mathrm{N}}\right]+\right. \\
\left.(1-x)^{2} /\left[\mathrm{A}_{\mathrm{Z}}\right]\right)
\end{gathered}
$$

The amplitudes assume a maximum near the $\mathrm{p} K$ values if the total concentration of the dibasic acid is smaller than the concentration of the proton (hydroxide ion) at $\mathrm{p} K_{1}\left(\mathrm{p} K_{2}\right)$. Otherwise the maximum is assumed at the $\mathrm{pH}$ where the proton concentration (hydroxide concentration) is equal to the concentration of the cation (anion).

$I V$. For $3 \mathrm{HP}$ at a $\mathrm{pH}$ in the vicinity of $\mathrm{p} K_{1}$, mode IV consists of protolysis reactions of both the first and the second dissociation. Analogously, at a $\mathrm{pH}$ in the vicinity of $\mathrm{p} K_{2}$, mode IV consists of hydrolysis reactions of both the first and the second dissociation. Generally, this mode consists of hydrolysis reactions at $\mathrm{pH} \ll 7$ and of protolysis reactions at $\mathrm{pH} \gg 7$. Consequently, this relaxation is never important, and its amplitude is small. Mode IV is usually the fastest relaxation because the dissociation constant of water, the fastest reaction rate constant in aqueous solution, contributes to this mode. Only at high concentrations of the dibasic acid may other relaxations be faster. See also Table V, where this mode is described for 3HP

We have discussed only the $\Gamma$ factor of the amplitude. All amplitudes also depend, of course, on other physical parameters, like reaction volumes, extinction coefficients, reaction enthalpies, and the like, and by a suitable choice of the experimental conditions it may still be possible to measure relaxation processes with small $\Gamma$ factors.

Relaxation Spectra of $3 H P$. Figure 2 shows the relaxation spectrum simulated for a temperature jump experiment. For the relative concentration changes in each relaxation process see Table $V$. Mode I is the slowest relaxation, and it has the largest amplitude. The approximate value for the relaxation time is in good 
TABLE IV: Kinetic Mechanism of 3-Hydroxypyridine ${ }^{a}$

\begin{tabular}{llcrc}
\hline & \multicolumn{1}{c}{$k_{\mathrm{f}}$} & $k_{\mathrm{r}}$ & $\Delta H$ & \multicolumn{1}{c}{$\Delta V$} \\
\hline $\mathrm{A}_{\mathrm{N}}+\mathrm{H}^{+} \rightleftharpoons \mathrm{A}^{+}$ & $2.00 \times 10^{10}$ & $1.20 \times 10^{5}$ & -23.8 & -0.80 \\
$\mathrm{~A}_{\mathrm{N}} \rightleftharpoons \mathrm{A}_{\mathrm{Z}}$ & $1.00 \times 10^{3}$ & $9.52 \times 10^{2}$ & -13.6 & -6.40 \\
$\mathrm{~A}_{\mathrm{N}} \rightleftharpoons \mathrm{H}^{+}+\mathrm{A}^{-}$ & $9.84 \times 10^{1}$ & $2.00 \times 10^{10}$ & 22.6 & -13.4 \\
$\mathrm{~A}_{\mathrm{N}}+\mathrm{H}_{2} \mathrm{O} \rightleftharpoons \mathrm{A}^{+}+\mathrm{OH}^{-}$ & 0.453 & $1.50 \times 10^{10}$ & 32.0 & -22.3 \\
$\mathrm{~A}_{\mathrm{Z}}+\mathrm{H}^{+} \rightleftharpoons \mathrm{A}^{+}$ & $2.00 \times 10^{10}$ & $1.26 \times 10^{5}$ & -10.2 & 5.60 \\
$\mathrm{~A}_{\mathrm{Z}} \rightleftharpoons \mathrm{H}^{+}+\mathrm{A}^{-}$ & $9.37 \times 10^{1}$ & $2.00 \times 10^{10}$ & 36.2 & -7.00 \\
$\mathrm{~A}_{\mathrm{Z}}+\mathrm{H}_{2} \mathrm{O} \rightleftharpoons \mathrm{A}^{+}+\mathrm{OH}^{-}$ & 0.431 & $1.50 \times 10^{10}$ & 45.6 & -15.9 \\
$\mathrm{~A}_{\mathrm{Z}}+\mathrm{OH}^{-} \rightleftharpoons \mathrm{A}^{-}+\mathrm{H}_{2} \mathrm{O}$ & $1.50 \times 10^{10}$ & $5.80 \times 10^{2}$ & -19.6 & 14.5 \\
$2 \mathrm{~A}_{\mathrm{N}} \rightleftharpoons 2 \mathrm{~A}_{\mathrm{Z}}$ & $5.00 \times 10^{6}$ & $4.53 \times 10^{6}$ & -27.2 & -12.8 \\
$\mathrm{~A}_{\mathrm{N}}+\mathrm{A}^{+} \rightleftharpoons \mathrm{A}_{\mathrm{Z}}+\mathrm{A}^{+}$ & $3.70 \times 10^{8}$ & $3.52 \times 10^{8}$ & -13.6 & -6.4 \\
$\mathrm{~A}_{\mathrm{N}}+\mathrm{A}^{-} \rightleftharpoons \mathrm{A}_{\mathrm{Z}}+\mathrm{A}^{-}$ & $4.60 \times 10^{8}$ & $4.38 \times 10^{8}$ & -13.6 & -6.4 \\
$\mathrm{~A}^{+}+\mathrm{A}^{-} \rightleftharpoons 2 \mathrm{~A}_{\mathrm{N}}$ & $9.00 \times 10^{8}$ & $7.38 \times 10^{5}$ & 1.20 & 11.6 \\
$\mathrm{~A}^{+}+\mathrm{A}^{-} \rightleftharpoons 2 \mathrm{~A}_{\mathrm{Z}}$ & $9.00 \times 10^{8}$ & $6.69 \times 10^{5}$ & -26.0 & -1.37 \\
$\mathrm{~A}^{+}+\mathrm{A}^{-} \rightleftharpoons \mathrm{A}_{\mathrm{N}}+\mathrm{A}_{\mathrm{Z}}$ & $9.00 \times 10^{8}$ & $7.03 \times 10^{5}$ & -12.4 & 5.13 \\
$\mathrm{H}^{+}+\mathrm{OH}^{-} \rightleftharpoons \mathrm{H}_{2} \mathrm{O}$ & $1.40 \times 10^{11}$ & $2.53 \times 10^{-5}$ & -55.8 & 21.5 \\
$\mathrm{~A}_{\mathrm{N}}+\mathrm{OH}^{-} \rightleftharpoons \mathrm{A}^{-}+\mathrm{H}_{2} \mathrm{O}$ & $1.50 \times 10^{10}$ & $5.52 \times 10^{2}$ & -33.2 & 11.2
\end{tabular}

${ }^{a}$ Rate constants are essentially as given by Schuster et al. ${ }^{3}$ and are in standard units $(\mathrm{L}, \mathrm{mol}, \mathrm{s})$. For simplicity we set the rates of all diffusion-controlled protolysis reactions equal to the same value and did the same for the hydrolysis reactions. The rate constant of the direct intramolecular proton transfer was arbitrarily set to $k_{23}=10^{3}$. Its value is still too small to influence the results. $\Delta H$ and $\Delta V$ are given in the same units as in Table III. Data for the water dissociation are from the literature. ${ }^{2,12,16}$
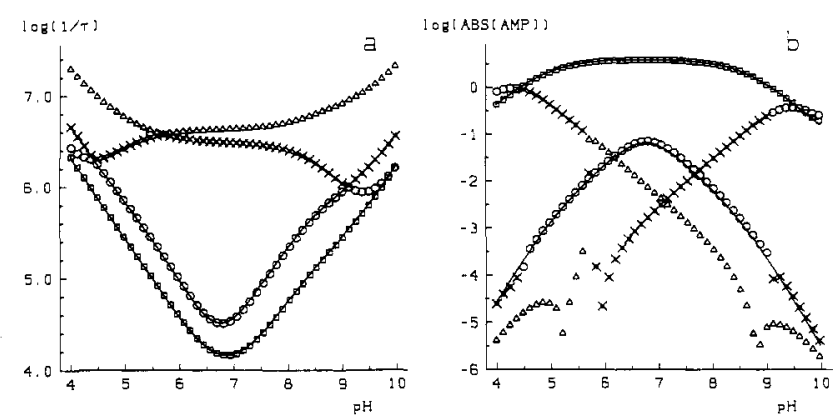

Figure 2. Relaxation spectrum of 3-hydroxypyridine simulated for a temperature jump experiment at a concentration of $2.0 \times 10^{-4} \mathrm{~mol} / \mathrm{L}$. See Table IV for the kinetic and thermodynamic data. Key: (a) mode $\mathrm{I} ;(0)$ at neutral $\mathrm{pH}$ and $(X)$ at more extreme $\mathrm{pH}$ values, mode II; $(X)$ at neutral $\mathrm{pH}$ values and $(\mathrm{O})$ at more extreme $\mathrm{pH}$ values, mode III; $(\Delta)$ mode IV; connected lines, approximations of mode I and mode II as described in the text. In part a, inverse relaxation times in units $\mathrm{s}^{-1}$. In part $b$, the amplitudes are given as extinctions and are arbitrarily scaled. We have used an extinction coefficient of 5745 for the zwitterion and 1810 for the anion. The extinction coefficients of other ions are taken to be zero. See text and Table V for a description of the normal reactions.

agreement with the exact value. Near the isoelectric point, mode $I$ is almost exclusively the overall reaction $A_{N}=A_{Z}$ (Table V). At other $\mathrm{pH}$ values, the $\mathrm{pH}$ changes also somewhat in mode $\mathrm{I}$. The amplitude of mode II is about 100 times smaller than the amplitude of mode I and will be, therefore, difficult to observe. The simulated mode II is associated with a change in $\mathrm{pH}$, especially at $\mathrm{pH}$ values much different from the isoelectric point. Thus, the approximation to the amplitude deviates slightly from the simulation; however, the approximation to the inverse relaxation time is indistinguishable from the simulated value. Near $\mathrm{p} K_{1}$ and $\mathrm{p} K_{2}$, mode III is prominent. At a $\mathrm{pH}$ about equal to $\mathrm{p} K_{1}=5.0$, the proton concentration is still smaller than the concentrations of the 3HP forms involved in mode IIIa. Consequently, the amplitude assumes its maximum value at lower $\mathrm{pH}$, i.e., $\mathrm{pH} 4.3$, where the concentrations of $A_{N}$ and $A_{Z}$ are comparable to the proton concentration. Similarly, mode IIIb assumes its maximum at a $\mathrm{pH}$ higher than $\mathrm{pK}_{2}$. The relaxation time of mode IIIa is slowest (longest) at a $\mathrm{pH}$ smaller than $\mathrm{p} K_{1}$. This is easily understood because the dominating part of this relaxation time is a weighted average of $k_{21}\left(\left[\mathrm{H}^{+}\right]+\left[\mathrm{A}_{\mathrm{N}}\right]\right)$ and $k_{31}\left(\left[\mathrm{H}^{+}\right]+\left[\mathrm{A}_{\mathrm{Z}}\right]\right)$, which assumes a minimum when $\left[\mathrm{H}^{+}\right]$is approximately equal to the sum of concentrations of $\mathrm{A}_{\mathrm{N}}$ and $\mathrm{A}_{\mathrm{Z}}$. A similar consideration holds for the relaxation time of mode IIIb.
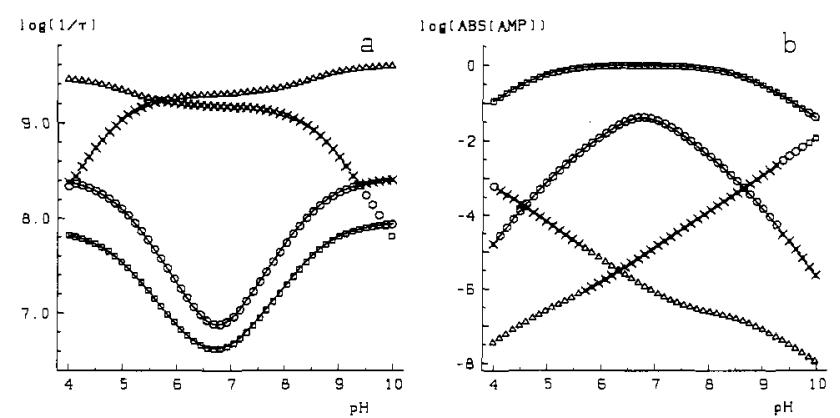

Figure 3. Relaxation spectrum of 3-hydroxypyridine simulated for an ultrasound experiment at a concentration of $0.1 \mathrm{~mol} / \mathrm{L}$. Symbols are analogous to those of Figure 2. The amplitudes, $\Gamma \Delta V_{\mathrm{S}}^{2}$, are in units $\mathrm{mL} /(\mathrm{mol} \times 1000)$.
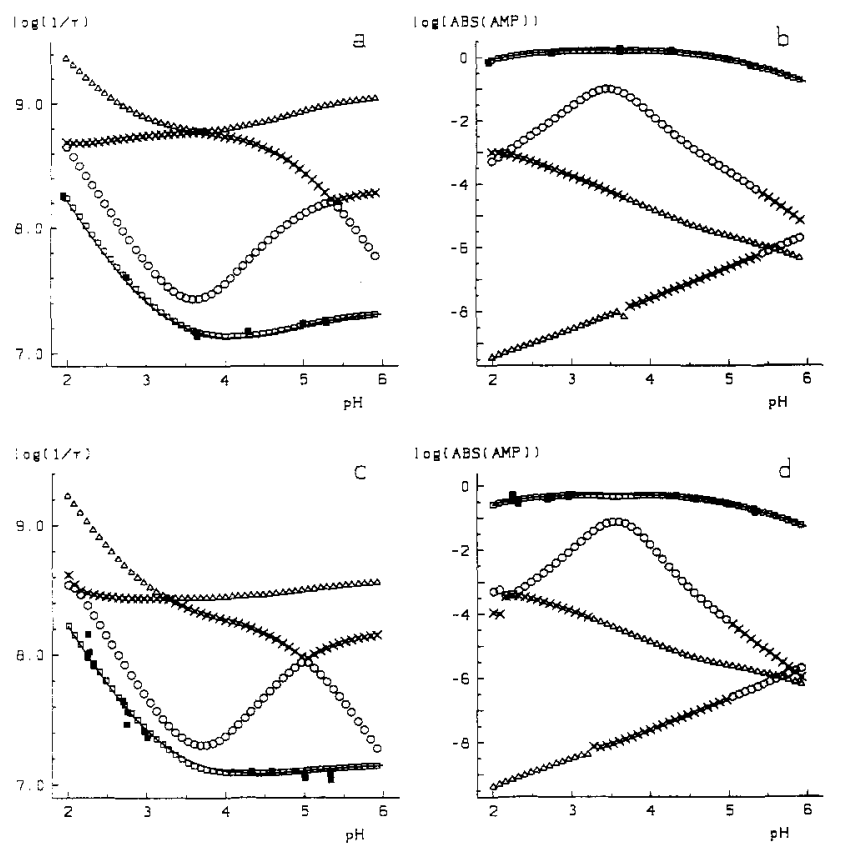

Figure 4. Relaxation spectrum of anthranilic acid simulated for an ultrasound experiment is shown together with measured data (घ). See Table VII for the kinetic and thermodynamic data and Figures 2 and 3 for a description of the plot. Key: ( $\square$ ) mode I; (O) at roughly pH 2.5-5, then $(x)$, mode II. For the other two normal reactions see Table VIII. Connected line is the function used for fitting the data. The total concentration of ANA is $0.029 \mathrm{~mol} / \mathrm{L}$ in $\mathrm{a}, \mathrm{b}$ and $0.0093 \mathrm{~mol} / \mathrm{L}$ in $c, d$.

The relaxation spectrum simulated for an ultrasound experiment is shown in Figure 3. The normal modes are the same as in Figure 2. Because the concentration of $3 \mathrm{HP}$ is higher in the simulation of the ultrasound experiment, there are small differences, however: the relaxation times of mode I and mode II are faster than in Figure 2, and the $\mathrm{pH}$ does not change in mode II. Although this is not visible in Figure 3, the amplitude of mode IIIa takes on its maximum at lower $\mathrm{pH}$ than it does in Figure 2. The inverse relaxation time of mode IIIa assumes its minimum also at a lower $\mathrm{pH}$ value. Similar behavior is observed for mode IIIb.

\section{Anthranilic Acid}

Mechanism of Proton-Transfer Reactions. The scheme of proton-transfer reactions of anthranilic acid in aqueous solution ${ }^{17}$ is the same as that of $3 \mathrm{HP}$ (Figure 1). The values of the equilibrium constants are available from the literature. ${ }^{6,18}$ We used $\mathrm{p} K_{1}=2.09, \mathrm{p} K_{2}=4.97$, and $K_{\mathrm{T}}=0.2$. Since both $\mathrm{p} K$ values are smaller than 7, hydrolysis reactions are not important.

Ultrasound Absorption. We have measured the ultrasonic attenuation of aqueous solutions of anthranilic acid (ANA) and

(17) Potschka, M. Diplomarbeit, University of Vienna, 1978.

(18) Serjeant, E. P.; Dempsey, B. Ionization Constants of Organic Acids in Aqueous Solution; International Union of Pure and Applied Chemistry; Pergamon: Oxford, U.K., 1979. 
TABLE V: Normal Reactions of 3-Hydroxypyridine ${ }^{a}$

\begin{tabular}{|c|c|c|c|c|c|c|c|c|}
\hline & $A_{N}$ & $\mathrm{~A}_{\mathrm{z}}$ & $\mathrm{A}^{+}$ & $\mathrm{A}^{-}$ & $\mathrm{H}^{+}$ & $\mathrm{OH}^{-}$ & $\mathrm{H}_{2} \mathrm{O}$ & \\
\hline \multicolumn{9}{|c|}{$c_{3 \mathrm{HP}}=2 \times 10^{-4}, \mathrm{pH} 8.63$} \\
\hline I & 1.000 & -1.000 & 0.000 & 0.000 & 0.000 & 0.000 & 0.000 & 1.00 \\
\hline II & -1.000 & -0.999 & 1.000 & 0.999 & 0.041 & 0.042 & -0.042 & $8.06 \times 10^{-4}$ \\
\hline IIIb & 0.487 & 0.512 & 0.000 & -1.000 & 0.000 & 1.000 & -1.000 & 0.311 \\
\hline IV & -0.131 & -0.123 & -0.325 & 0.578 & 1.000 & 0.097 & -0.097 & $1.91 \times 10^{-4}$ \\
\hline \multicolumn{9}{|c|}{$c_{3 \mathrm{HP}}=2 \times 10^{-4}, \mathrm{pH} 6.93$} \\
\hline I & 0.998 & -1.000 & 0.001 & 0.001 & 0.000 & 0.000 & 0.000 & 1.000 \\
\hline II & -0.988 & -0.974 & 0.962 & 1.000 & 0.059 & 0.020 & -0.020 & $2.65 \times 10^{-2}$ \\
\hline IIIb & 0.464 & 0.488 & 0.027 & -0.980 & -0.007 & 1.000 & -1.000 & $3.33 \times 10^{-3}$ \\
\hline $\mathrm{IV}=\mathrm{III} \mathrm{a}$ & 0.455 & 0.478 & -0.963 & 0.030 & 1.000 & 0.007 & -0.007 & $2.94 \times 10^{-3}$ \\
\hline \multicolumn{9}{|c|}{$c_{3 \mathrm{HP}}=2 \times 10^{-4}, \mathrm{pH} 4.97$} \\
\hline I & 1.000 & -1.000 & -0.027 & 0.000 & 0.027 & 0.000 & 0.000 & 1.000 \\
\hline II & -0.948 & -0.940 & 0.889 & 1.000 & -0.124 & 0.012 & -0.012 & $9.88 \times 10^{-4}$ \\
\hline IIIa & 0.487 & 0.512 & -1.000 & 0.000 & 1.000 & 0.000 & 0.000 & 0.404 \\
\hline IV & -0.253 & -0.152 & 0.353 & -0.312 & 0.335 & 1.000 & -1.000 & $1.05 \times 10^{-4}$ \\
\hline \multicolumn{9}{|c|}{$c_{3 \mathrm{HP}}=0.1 \mathrm{~mol} / \mathrm{L}, \mathrm{pH} 8.64$} \\
\hline I & 1.000 & -1.000 & 0.000 & 0.000 & 0.000 & 0.000 & 0.000 & 1.000 \\
\hline II & 1.000 & 0.975 & -0.988 & -0.988 & 0.000 & 0.000 & 0.000 & $9.36 \times 10^{-4}$ \\
\hline IIIb & -0.487 & -0.512 & -0.000 & 1.000 & 0.000 & -1.000 & 1.000 & $6.31 \times 10^{-4}$ \\
\hline IV & 0.164 & 0.156 & 0.340 & -0.660 & -1.000 & 0.000 & 0.000 & $2.23 \times 10^{-7}$ \\
\hline \multicolumn{9}{|c|}{$c_{3 \mathrm{HP}}=0.1 \mathrm{~mol} / \mathrm{L}, \mathrm{pH} 6.92$} \\
\hline I & 0.997 & -1.000 & 0.001 & 0.001 & 0.000 & 0.000 & 0.000 & 1.000 \\
\hline II & 1.000 & 0.942 & -0.971 & -0.971 & 0.000 & 0.000 & 0.000 & $3.28 \times 10^{-2}$ \\
\hline IIIb & -0.470 & -0.495 & -0.017 & 0.938 & 0.000 & -1.000 & 1.000 & $6.23 \times 10^{-6}$ \\
\hline$I V=I I I a$ & -0.452 & -0.476 & 0.964 & -0.036 & -1.000 & 0.000 & 0.000 & $2.12 \times 10^{-6}$ \\
\hline \multicolumn{9}{|c|}{$c_{3 \mathrm{HP}}=0.1 \mathrm{~mol} / \mathrm{L}, \mathrm{pH} 4.97$} \\
\hline I & 1.000 & -1.000 & 0.000 & 0.000 & 0.000 & 0.000 & 0.000 & 1.000 \\
\hline II & 1.000 & 0.982 & -0.991 & -0.991 & 0.000 & 0.000 & -0.000 & $1.12 \times 10^{-3}$ \\
\hline IIIa & -0.487 & -0.512 & 1.000 & 0.000 & -1.000 & 0.000 & 0.000 & $3.06 \times 10^{-4}$ \\
\hline IV & 0.115 & 0.106 & -0.610 & 0.389 & 0.000 & -1.000 & 1.000 & $1.78 \times 10^{-7}$ \\
\hline
\end{tabular}

${ }^{a}$ The changes in concentration of every form of 3-hydroxypyridine and water for a given relaxation are tabulated. In each normal reaction, the species with the biggest change is normalized to one. The relative size of the changes of the normal modes is given in the last column. $c_{3 H P}=2 \times$ $10^{-4}$ corresponds to the temperature jump experiment (Figure 2); $c_{3 \mathrm{HP}}=0.1 \mathrm{~mol} / \mathrm{L}$ corresponds to the ultrasound experiment (Figure 3). At each $\mathrm{pH}$ the reactions are listed in the order of their relaxation times, beginning with the slowest process.

could resolve one relaxation process (see Table VI and Figure 4). We assumed that the relaxation is due to proton-transfer reactions. ${ }^{6}$ Since the amplitude assumes its maximum at the isoelectric point, it follows that either mode I or mode II has been measured. It is easily seen that at all $\mathrm{pH}$ values the $\Gamma$ factor of mode $I$ is larger than that of mode II. The reaction volumes of anthranilic acid are not known from independent measurements. In overall reaction $I$, the number of local charges changes by 2 . In overall reaction II, the number of local charges changes by -2 in the reaction to $A_{N}$ and by +2 in the reaction to $A_{z}$. Depending on the stoichiometric coefficients of $A_{N}$ and $A_{Z}$, this number might be anywhere between -2 and +2 . Reaction volumes of reactions that generate an ion pair are about -10 to $-20 \mathrm{~mL} / \mathrm{mol} .^{12} \mathrm{Re}$ actions in which the number of charges is constant usually have a smaller reaction volume in absolute value. We expect, therefore, mode I to have a larger reaction volume than mode II. Since the amplitude of the ultrasound experiment depends on the square of the reaction volumes, this difference would translate to an even bigger difference in amplitude. White and Slutsky ${ }^{6}$ have estimated reaction volumes for ANA by a comparison with analogous reactions. If the coefficients of $A_{N}$ and $A_{Z}$ in normal reaction II are taken to be equal and unity, one calculates from their data the same reaction volumes for mode I and mode II. However, they did not consider a potential significance of mode II. If we use their data or the values determined for $3 \mathrm{HP}$, we indeed calculate a much larger amplitude for mode I than for mode II (see also Figure 4). The $\mathrm{pH}$ dependence of the measured amplitude clearly resembles that of mode I (Figure 4). We therefore attribute the ultrasonic absorption to mode I.

We fitted the relaxation data to the equation $k_{0}+k_{\mathrm{H}}\left[\mathrm{H}^{+}\right]+$ $k_{-}\left[\mathrm{A}^{-}\right]+k_{\mathrm{N}}\left[\mathrm{A}_{\mathrm{N}}\right]$, which is a simple version of the approximate formula for the inverse relaxation time of mode I. The constant $k_{+}$corresponding to $k_{-}$could not be determined because, at $\mathrm{pH}$ values smaller than the isoelectric point, the contribution of the dissociative pathway is much larger than the contribution of the bimolecular reaction catalyzed by the cation. Since ANA is not easily soluble at the isoelectric point, we could not measure the relaxation time at high concentrations of ANA, where the contribution of the bimolecular reactions would be larger. In Table VI we show the measured values and the coefficients obtained. The rate of the intramolecular proton-transfer step was found to be $k_{0}=k_{23}\left(1+K_{\mathrm{T}}\right) / K_{\mathrm{T}}=k_{23}+k_{32}=9.9 \times 10^{6} \mathrm{~s}^{-1}$. This is significantly larger than the constant term that arises from the dissociative pathway (see section Ib), which calculates as about $6 \times 10^{5} \mathrm{~s}^{-1}$, using a diffusion-controlled constant of $2 \times 10^{10} \mathrm{~L}$ $\mathrm{mol}^{-1} \mathrm{~s}^{-1}$ for the protolysis reactions of the anion. We stress that setting $k_{0}$ to zero does not lead to a satisfactory fit.

A rough quantitative argument should illustrate this fact. We use the diffusion-controlled limit of $5 \times 10^{10} \mathrm{~L} \mathrm{~mol}^{-1} \mathrm{~s}^{-1}$ as an estimate for $k_{\mathrm{H}}$ and the diffusion-controlled limit of $5 \times 10^{8} \mathrm{~L}$ $\mathrm{mol}^{-1} \mathrm{~s}^{-1}$ as an estimate for $k_{-}{ }^{6}$ Then, at $\mathrm{pH} 4.3$, the contribution of the dissociative pathway to the inverse relaxation time calculates as $2.5 \times 10^{6} \mathrm{~s}^{-1}$, and the contribution of the bimolecular pathway calculates as $3 \times 10^{6} \mathrm{~s}^{-1}$ at the highest concentration of ANA used. However, at $\mathrm{pH} 4.3$, we measured inverse relaxation times greater than $10^{7} \mathrm{~s}^{-1}$ at any concentration of ANA used. A similar estimate for the inverse relaxation time at the isoelectric point, $\mathrm{pH} \sim 3.6$, furnishes for the dissociative pathway a contribution of $1.25 \times$ $10^{7} \mathrm{~s}^{-1}$, which could largely account for our measurement. Such reasoning probably led White and Slutsky ${ }^{6}$ to their conclusion that the intramolecular pathway plays no role in aqueous solution. However, the concentration and $\mathrm{pH}$ dependence of the inverse relaxation time firmly establishes the significance of the intramolecular reaction. We also obtained smaller values for $k_{\mathrm{H}}$ and $k_{-}$than those used in the argument above. From the data at lower $\mathrm{pH}$, for instance, it is immediately clear that $k_{\mathrm{H}}$ is smaller than $2 \times 10^{10} \mathrm{~L}^{-1} \mathrm{~mol} \mathrm{~s}^{-1}$, which is consistent with the rate constant found for $3 \mathrm{HP}$. 
TABLE VI: Ultrasound Measurements of Anthranilic Acid in Water ${ }^{a}$

\begin{tabular}{|c|c|c|c|}
\hline $10^{2} c_{\text {ANT }}$ & $\mathrm{pH}$ & $10^{-7} \tau^{-1}, \mathrm{~s}^{-1}$ & $10^{4}(\pi \Delta f / f)$ \\
\hline 2.91 & 1.96 & 18.3 & 3.07 \\
\hline 2.92 & 2.77 & 4.05 & 5.66 \\
\hline 2.91 & 3.64 & 1.45 & 8.19 \\
\hline 2.95 & 3.65 & 1.38 & 6.40 \\
\hline 2.92 & 4.30 & 1.51 & 7.04 \\
\hline 2.92 & 5.0 & 1.74 & 3.78 \\
\hline 0.932 & 2.26 & 14.4 & 2.25 \\
\hline 0.933 & 2.33 & 8.25 & 1.18 \\
\hline 0.933 & 2.70 & 4.42 & 1.59 \\
\hline 0.932 & 2.75 & 2.91 & 1.78 \\
\hline 0.932 & 2.97 & 2.58 & 1.90 \\
\hline 0.933 & 4.33 & 1.27 & 2.09 \\
\hline 0.933 & 4.59 & 1.25 & 1.81 \\
\hline 0.933 & 4.9 & 1.26 & 1.37 \\
\hline 0.932 & 5.01 & 1.12 & 1.14 \\
\hline 0.932 & 5.33 & 1.20 & 0.83 \\
\hline 0.953 & 5.34 & 1.09 & 0.65 \\
\hline 1.72 & 5.34 & 1.36 & 1.33 \\
\hline 1.32 & 2.90 & 3.56 & 2.71 \\
\hline 1.31 & 4.30 & 1.29 & 3.11 \\
\hline 1.31 & 5.01 & 1.46 & 1.72 \\
\hline 0.709 & 3.64 & 1.36 & 1.78 \\
\hline 2.91 & 1.96 & 17.6 & 2.9 \\
\hline 2.92 & 2.76 & 4.1 & 5.6 \\
\hline 2.95 & 3.64 & 1.5 & 6.5 \\
\hline 2.91 & 3.65 & 1.48 & 8.0 \\
\hline 2.92 & 4.30 & 1.48 & 7.0 \\
\hline 2.91 & 5.0 & 1.75 & 3.8 \\
\hline 2.86 & 5.30 & 1.74 & 2.3 \\
\hline 1.31 & 4.3 & 1.27 & 3.1 \\
\hline 1.31 & 5.01 & 1.37 & \\
\hline 0.932 & 2.25 & 9.5 & \\
\hline 0.932 & 2.28 & 10.4 & 1.5 \\
\hline 0.933 & 2.33 & 8.2 & 1.3 \\
\hline 0.933 & 2.70 & 4.4 & 1.7 \\
\hline 0.932 & 2.76 & 3.6 & 1.9 \\
\hline 0.932 & 2.97 & 2.58 & 1.9 \\
\hline 0.933 & $\mathbf{3 . 0 1}$ & 2.3 & \\
\hline 0.933 & 4.34 & 1.23 & 2.1 \\
\hline 0.933 & 4.59 & 1.24 & 1.7 \\
\hline 0.933 & 4.9 & 1.26 & 1.35 \\
\hline 0.932 & 5.0 & 1.2 & 1.2 \\
\hline 0.932 & 5.33 & 1.25 & 0.75 \\
\hline 0.709 & 3.70 & 1.37 & 1.8 \\
\hline
\end{tabular}

${ }^{a} \mathrm{~A}$ linear fit furnished as follows: $\tau^{-1}=\left(9.9 \times 10^{6}\right) \pm\left(6 \times 10^{5}\right)+$ $\left[\left(1.56 \times 10^{10}\right) \pm\left(5.4 \times 10^{8}\right)\right]\left[\mathrm{H}^{+}\right]+\left[\left(3.25 \times 10^{8}\right) \pm\left(6.7 \times 10^{7}\right)\right]\left[\mathrm{A}^{-}\right]$ $+\left[\left(6.9 \times 10^{7}\right) \pm\left(3.7 \times 10^{7}\right)\right]\left[\mathrm{A}_{\mathrm{N}}\right]$. From the amplitudes we obtained $K_{\mathrm{T}}\left(\Delta V_{\mathrm{S}}\right)_{\mathrm{T}}^{2} /\left(1+K_{\mathrm{T}}\right)^{2}=19.5 \pm 0.6(\mathrm{~mL} / \mathrm{mol})^{2}, \mathrm{p} K_{1}=2.24$, and $\mathrm{p} K_{2}=$ 4.99 .

The constant $k_{\mathrm{N}}$ obtained from the fit in Table VI is statistically not very significant. If we omit it, we obtain slightly larger values for $k_{0}$ and $k_{-}: k_{0}=1.06 \times 10^{7} \mathrm{~L} \mathrm{~mol}^{-1} \mathrm{~s}^{-1}$ and $k_{0}=3.6 \times 10^{8}$ $\mathrm{L} \mathrm{mol}{ }^{-1} \mathrm{~s}^{-1}$. Their standard deviations are about the same as in the fit shown. We use, however, the values obtained from the first fit. The individual rate constants calculated from the fitted parameters are shown in Table VII. We have calculated the rate constants for the reaction $2 A_{N} \rightleftharpoons 2 A_{Z}$ from $k_{N}$, where we subtracted the contribution from the bimolecular reactions described in section IIb above, but do not consider them to be significant. $k_{\mathrm{H}}$, the diffusion-controlled rate constant for the protolysis reactions determined by us, is a weighted average of $k_{12}$ and $k_{13}$. For the estimation of the constant term from section Ib, the diffusion-controlled constants $k_{42}$ and $k_{43}$ have to be used. We have used a conservative value of $2 \times 10^{10} \mathrm{~L} \mathrm{~mol}^{-1} \mathrm{~s}^{-1}$ to estimate a correction term of $6 \times 10^{5} \mathrm{~s}^{-1}$. With this value the sum of the forward rate constant and backward rate constant of the intramolecular proton-transfer step is determined as $9.3 \times 10^{6} \mathrm{~s}^{-1}$. However, with the diffusion-controlled limit of $5 \times 10^{10} \mathrm{~L} \mathrm{~mol}^{-1}$ $\mathrm{s}^{-1}$ the correction would be bigger, i.e., $1.5 \times 10^{6} \mathrm{~s}^{-1}$.

From the amplitudes we have calculated the reaction volume at constant entropy and have found $\left|\left(\Delta V_{\mathrm{S}}\right)_{\mathrm{T}}\right|=11.9 \mathrm{~mL} / \mathrm{mol}$, using $K_{\mathrm{T}}=0.2$ as cited by White and Slutsky. ${ }^{6}$ We assume a negative sign since almost all equilibria between neutral form and zwitterion
TABLE VII: Kinetic Mechanism of Anthranilic Acid ${ }^{a}$

\begin{tabular}{lccc}
\hline & $k_{f}$ & $k_{r}$ & $\Delta V$ \\
\hline $\mathrm{A}_{\mathrm{N}}+\mathrm{H}^{+} \rightleftharpoons \mathrm{A}^{+}$ & $1.56 \times 10^{10}$ & $1.06 \times 10^{8}$ & -4.00 \\
$\mathrm{~A}_{\mathrm{N}} \rightleftharpoons \mathrm{A}_{\mathrm{Z}}$ & $1.55 \times 10^{6}$ & $7.75 \times 10^{6}$ & -21.0 \\
$\mathrm{~A}_{\mathrm{N}} \rightleftharpoons \mathrm{H}^{+}+\mathrm{A}^{-}$ & $2.57 \times 10^{5}$ & $2.00 \times 10^{10}$ & -10.0 \\
$\mathrm{~A}_{\mathrm{N}}+\mathrm{H}_{2} \mathrm{O} \rightleftharpoons \mathrm{A}^{+}+\mathrm{OH}^{-}$ & $5.33 \times 10^{-4}$ & $2.00 \times 10^{10}$ & -25.5 \\
$\mathrm{~A}_{\mathrm{Z}}+\mathrm{H}^{+} \rightleftharpoons \mathrm{A}^{+}$ & $1.56 \times 10^{10}$ & $2.12 \times 10^{7}$ & 17.0 \\
$\mathrm{~A}_{\mathrm{Z}} \rightleftharpoons \mathrm{H}^{+}+\mathrm{A}^{-}$ & $1.28 \times 10^{6}$ & $2.00 \times 10^{10}$ & 11.0 \\
$\mathrm{~A}_{\mathrm{Z}}+\mathrm{H}_{2} \mathrm{O} \rightleftharpoons \mathrm{A}^{+}+\mathrm{OH}^{-}$ & $2.66 \times 10^{-3}$ & $2.00 \times 10^{10}$ & -4.50 \\
$\mathrm{~A}_{\mathrm{Z}}+\mathrm{OH}^{-} \rightleftharpoons \mathrm{A}^{-}+\mathrm{H}_{2} \mathrm{O}$ & $2.00 \times 10^{10}$ & $5.63 \times 10^{-2}$ & 32.5 \\
$2 \mathrm{~A}_{\mathrm{N}} \rightleftharpoons 2 \mathrm{~A}_{\mathrm{Z}}$ & $2.00 \times 10^{6}$ & $5.00 \times 10^{7}$ & -42.0 \\
$\mathrm{~A}_{\mathrm{N}}+\mathrm{A}^{+} \rightleftharpoons \mathrm{A}_{\mathrm{Z}}+\mathrm{A}^{+}$ & $5.40 \times 10^{7}$ & $2.70 \times 10^{8}$ & -21.0 \\
$\mathrm{~A}_{\mathrm{N}}+\mathrm{A}^{-} \rightleftharpoons \mathrm{Az}_{\mathrm{Z}}+\mathrm{A}^{-}$ & $5.40 \times 10^{7}$ & $2.70 \times 10^{8}$ & -21.0 \\
$\mathrm{~A}^{+}+\mathrm{A}^{-} \rightleftharpoons 2 \mathrm{~A}_{\mathrm{N}}$ & $9.00 \times 10^{8}$ & $1.71 \times 10^{6}$ & 14.0 \\
$\mathrm{~A}^{+}+\mathrm{A}^{-} \rightleftharpoons 2 \mathrm{~A}_{\mathrm{Z}}$ & $9.00 \times 10^{8}$ & $4.27 \times 10^{7}$ & -28.0 \\
$\mathrm{~A}^{+}+\mathrm{A}^{-} \rightleftharpoons \mathrm{A}_{\mathrm{N}}+\mathrm{A}_{\mathrm{z}}$ & $9.00 \times 10^{8}$ & $8.53 \times 10^{6}$ & -7.00 \\
$\mathrm{H}^{+}+\mathrm{OH}^{-} \rightleftharpoons \mathrm{H}_{2} \mathrm{O}$ & $1.40 \times 10^{11}$ & $2.53 \times 10^{-5}$ & 21.5 \\
$\mathrm{~A}_{\mathrm{N}}+\mathrm{OH}^{-} \rightleftharpoons \mathrm{A}^{-}+\mathrm{H}_{2} \mathrm{O}$ & $2.00 \times 10^{10}$ & $2.81 \times 10^{-1}$ & 11.5 \\
$\mathrm{~A}^{-}$ & & &
\end{tabular}

${ }^{a} \mathrm{~A}$ few rate constants and the reaction volume of the second reaction were determined by us (see text). Other parameters were largely taken from 3-hydroxypyridine or from analogous reactions.

have reaction volumes between -10 and $-20 \mathrm{~mL} / \mathrm{mol}^{12}$ With the reaction enthalpy cited by White and Slutsky, $\Delta H_{\mathrm{T}}=-47.3$ $\mathrm{kJ} / \mathrm{mol}$, we calculate $\Delta V_{\mathrm{T}}$ to be $-15.1 \mathrm{~mL} / \mathrm{mol}$.

The simulation of the relaxation spectrum at two different concentrations of ANA together with measured data is shown in Figure 4. We used the same mechanism as with 3HP (Table VII), although the contribution of the hydrolysis reactions is negligible. The computed concentration changes are shown in Table VIII. The simulation is in sufficient agreement with data and the fitted curve; small deviations between the approximate curve and the simulated curve can easily be explained. The simulated relaxation I is only to about $80-90 \%$ ideal mode I and has also some mode II and mode III mixed in. This introduces a systematic error in our reaction volume and in our rate constants. Since the precise amount of that error depends on an exact knowledge of all rate constants and reaction volumes, we did not calculate that correction. Finally, we stress that with a significantly smaller intramolecular rate constant than the one used, the data cannot adequately be simulated (not shown).

We mentioned already that ANA has also been investigated by White and Slutsky; ${ }^{6}$ some of the ultrasonic data they used were obtained earlier by Eggers. ${ }^{19}$ In aqueous solution, they found no evidence for an intramolecular proton-transfer step. At their experimental conditions, the contributions of the dissociative and the intramolecular pathways are comparable in magnitude-i.e., if our results are used for this comparison. Since they have measured ultrasonic absorption at only one concentration of ANA and only in a limited $\mathrm{pH}$ range, they probably could not distinguish between the different contributions to the inverse relaxation time. White and Slutsky concluded, however, that proton transfer of ANA in methanol takes place via an intramolecular step and reported a value of $1.4 \times 10^{8} \mathrm{~s}^{-1}$ for the intramolecular protontransfer rate constant in the thermodynamically favored direction. This contribution is bigger than the contribution of dissociative and bimolecular pathways and should be reliable, therefore. They also found a much larger reaction volume in methanol than the one we found for aqueous solution: $-32.4 \mathrm{~mL} / \mathrm{mol}$.

On the basis of our simulations for ANA and the results of 3HP and other dibasic acids, we have assumed that the excess ultrasound absorption is caused by proton-transfer reactions. Reversible aggregation reactions of ANA would also contribute a constant term to the inverse relaxation time. However, especially at lower concentrations of ANA, we think it not very likely that aggregation contributes much to the relaxation process. Pörschke and Eggers ${ }^{20}$ have studied stacking of aromatic compounds, and Yiv et al. ${ }^{21}$

(19) Eggers, F. Acustica 1967/1968, 19, 323-329.

(20) Pörschke, D.; Eggers, F. Eur. J. Biochem. 1972, 26, 490-498.

(21) Yiv, S.; Lang, J.; Zana, R. In Protons and Ions Involved in Fast Dynamical Phenomena; Proceedings of the 30th International Meeting of the Soc. de Chim. Phys. de France; Laszlo, P.; Ed.; Elsevier: Amsterdam, 1978; pp 311-322. 
TABLE VIII: Normal Reactions of Anthranilic Acid in Figure 4

\begin{tabular}{|c|c|c|c|c|c|c|c|c|}
\hline & $A_{N}$ & $\overline{A_{z}}$ & $\mathrm{~A}^{+}$ & $\mathrm{A}^{-}$ & $\mathrm{H}^{+}$ & $\mathrm{OH}^{-}$ & $\mathrm{H}_{2} \mathrm{O}$ & \\
\hline \multicolumn{9}{|c|}{$c_{\text {ANA }}=0.029 \mathrm{~mol} / \mathrm{L}, \mathrm{pH} 4.0$} \\
\hline I & 1.000 & -0.896 & -0.045 & -0.058 & -0.013 & 0.000 & 0.000 & 1.000 \\
\hline II & -0.832 & -0.964 & 0.796 & 1.000 & 0.204 & 0.000 & 0.000 & $2.88 \times 10^{-2}$ \\
\hline IV & -0.725 & -0.146 & -0.105 & 0.976 & 0.081 & -1.000 & 1.000 & $1.89 \times 10^{-8}$ \\
\hline III & 0.604 & 0.056 & -0.830 & 0.170 & 1.000 & 0.000 & 0.000 & $4.51 \times 10^{-4}$ \\
\hline \multicolumn{9}{|c|}{$c_{\mathrm{ANA}}=0.029 \mathrm{~mol} / \mathrm{L}, \mathrm{pH} 3.6$} \\
\hline I & 1.000 & -0.798 & -0.088 & -0.114 & -0.026 & 0.000 & 0.000 & 1.000 \\
\hline II & -0.400 & -1.000 & 0.616 & 0.784 & 0.168 & 0.000 & 0.000 & $9.21 \times 10^{-2}$ \\
\hline III & 0.733 & 0.119 & -0.926 & 0.074 & 1.000 & 0.000 & 0.000 & $1.07 \times 10^{-3}$ \\
\hline IV & -1.000 & -0.172 & 0.525 & 0.648 & -0.643 & -0.766 & 0.766 & $8.89 \times 10^{-9}$ \\
\hline \multirow{2}{*}{\multicolumn{9}{|c|}{$c_{\mathrm{ANA}}=0.029 \mathrm{~mol} / \mathrm{L}, \mathrm{pH} 3.04$}} \\
\hline 1 & & -0.898 & -0.044 & -0.058 & -0.015 & 0.000 & 0.000 & 1.000 \\
\hline II & -0.548 & -1.000 & 0.673 & 0.875 & 0.203 & 0.000 & 0.000 & $4.01 \times 10^{-2}$ \\
\hline III & 0.805 & 0.153 & -0.979 & 0.021 & 1.000 & 0.000 & 0.000 & $4.20 \times 10^{-3}$ \\
\hline IV & -0.688 & -0.093 & 0.065 & 0.715 & -0.350 & -1.000 & 1.000 & $2.19 \times 10^{-9}$ \\
\hline
\end{tabular}

have investigated the influence of aggregation processes on the relaxation of proton-transfer reactions. From their studies it follows that if association occurs at $\mathrm{p} K_{\mathrm{I}}$, this process is much faster than mode I and decoupled. Mode I would be modified by the faster association process and would become slower. ${ }^{22,23}$ An even faster intramolecular proton-transfer step would then be needed to simulate the relaxation adequately.

\section{Discussion}

The kinetic mechanism of proton transfer in aqueous solutions of 3-hydroxypyridine comprises 16 reactions. Using thermodynamic data estimated by us in this work and published thermodynamic and kinetic data, we have calculated its relaxation spectrum. The conclusions reached are valid for many dibasic acids. Near chemical equilibrium, the kinetics can be described by four normal reactions. Mode $I$ is the equilibration between the neutral form and the zwitterion, $A_{N}=A_{Z}$. Mode II is the overall reaction $\mathrm{A}^{+}+\mathrm{A}^{-}=x \mathrm{~A}_{\mathrm{N}}+(2-x) \mathrm{A}_{\mathrm{Z}}, 0 \leq x \leq 2$. Mode III consists of two branches, $\mathrm{A}^{+}=x \mathrm{~A}_{\mathrm{N}}+(1-x) \mathrm{A}_{\mathrm{Z}}+\mathrm{H}^{+}, x \sim$ 0.5 , at $\mathrm{p} K_{1}$ and $x \mathrm{~A}_{\mathrm{N}}+(1-x) \mathrm{A}_{\mathrm{Z}}+\mathrm{OH}^{-}=\mathrm{A}^{-}+\mathrm{H}_{2} \mathrm{O}, x \sim 0.5$, at $\mathrm{p} K_{2}$. The fourth relaxation consists of hydrolysis reactions at $\mathrm{pH} \ll 7$ and of protolysis reactions at $\mathrm{pH} \gg 7$ and can be neglected. We have discussed the relaxation times and amplitudes ( $\Gamma$ factors) of the first three relaxation processes in detail and paid special attention to mode I and mode II, which are most prominent at the isoelectric point of the dibasic acid. Especially in a neutral system, i.e., a dibasic acid with an isoelectric point near $\mathrm{pH} 7$, mode I and mode II are similar enough to be mistaken for each other. If $K_{\mathrm{T}} /\left(1+K_{\mathrm{T}}\right)^{2}$ is approximately equal to the square root of $K_{2} / K_{1}$, making the $\Gamma$ factors of mode I and mode II comparable in size at the isoelectric point, great care has to be exercised to establish which relaxation process has been measured.

In the second part of this work, we have investigated the kinetics of proton transfer in aqueous solutions of anthranilic acid with the ultrasound method. We have measured a single relaxation and attributed it to the tautomeric equilibrium $A_{N}=A_{z}$. Intramolecular proton transfer plays a significant role in the equilibration of this reaction. The sum of the forward rate constant and backward rate constant of the intramolecular proton-transfer reaction $A_{N} \rightleftharpoons A_{Z}$ is about $10^{7} \mathrm{~s}^{-1}$. This rate is clearly slower than diffusion-controlled intermolecular proton transfers. White and Slutsky ${ }^{6}$ have also studied the kinetics of proton-transfer reactions in aqueous solutions of anthranilic acid, using ultrasound data obtained by Eggers, ${ }^{19}$ and found no evidence for intramolecular proton transfer. However, they had only a few data and could not distinguish clearly between a dissociative pathway, bimolecular pathway, and intramolecular pathway of proton transfer. A few examples of intramolecular proton-transfer rates in aqueous solution were compiled by Schuster et al. ${ }^{4}$ and Dubois

(22) Bernasconi, C. F. Relaxation Kinetics; Wiley: New York, 1976; pp 99-102.

(23) Reiter, J.; Schuster, P.; Winkler, H.; Eggers, F. Eur. Biophys. J. 1988 in press. et al. ${ }^{5}$ Dubois et al., for instance, measured 6-chloro-2-hydroxypyridine and determined the intramolecular rate constant to be $3.9 \times 10^{4} \mathrm{~s}^{-1}$, which is much slower than ours. This can probably be explained by the fact that the reactive groups, i.e., especially the carboxylic group, are more mobile in anthranilic acid, and they can, therefore, come closer together than the reactive groups in the 2-hydroxypyridine derivative. White and Slutsky ${ }^{6}$ determined the rate of intramolecular proton transfer in anthranilic acid in methanol and found a rate constant of $1.4 \times 10^{8} \mathrm{~s}^{-1}$, which is more than 10 times faster than our result in water. This might be explained by a faster reorganization time of the solvent shell in methanol compared to that of water.

\section{Experiments and Methods}

Estimation of Reaction Enthalpies. 3HP and all other chemicals were obtained from Merck, Darmstadt, in p.A. quality. Spectra at different temperatures were taken with a Hitachi spectral photometer equipped with thermostatable cuvette holders and were recorded digitally on a PDP11 computer. We used the absorptions between 260 and $330 \mathrm{~nm}$ for the parameter estimations. The following three buffers were chosen: acetate buffer for the range of $\mathrm{p} K_{1}$, phosphate buffer for the range of $\mathrm{p} K_{\mathrm{I}}$, and ammonia buffer for the range of $\mathrm{p} K_{2}$.

The $\mathrm{pH}$ variation of the buffers with temperature is tabulated, ${ }^{24}$ and we corrected for it. All measurements were done at an ionic strength of $0.2 . K_{1}$ and $K_{2}$ could be obtained for each temperature in a straightforward manner. To estimate the value of $\Delta H_{\mathrm{T}}$, we had to compare data from different temperatures. To be able to do that, we assumed the volume change of the solution with temperature to be the same as that of pure water. ${ }^{25}$

Estimation of Reaction Volumes. In order to estimate the reaction volumes, we measured the spectra at different pressures varying from 1 to 2000 bar. We used a single-beam Cary spectrophotometer equipped with a recorder and digitized the absorptions at 313.5 and $298 \mathrm{~nm}$ by hand. The sample was contained in a steel cell with sapphire windows. The measurements were done in acetate buffer, cacodylate buffer, Tris buffer, and phosphate buffer at an ionic strength of 0.2 . The $\mathrm{pH}$ changes of the buffers with pressure were calculated by using published reaction volumes. ${ }^{26}$ All measurements were done at a temperature between 23 and $25^{\circ} \mathrm{C}$. We assumed the compressibility of the solution to be the same as that of pure water. ${ }^{27}$

Error Estimations. ${ }^{28}$ We calculated standard deviations for the random error with the assumption of a Gaussian error distribution. When fitting equations to data, we assumed that each

(24) Biochemist's Handbook, Long, C., Ed.; Spon Ltd.: London, 1961; pp 42-44.

(25) Water, Franks, F., Ed,; Plenum: New York, London, 1972; Vol. 1, p 376 .

(26) Neumann, R. C., Jr.; Kauzmann, W.; Zipp, A. J. Phys. Chem. 1973, $77,2687-2691$

(27) Landolt-Börnstein, Zahlenwerte und Funktionen aus Physik, Chemie, Geophysik und Technik; Springer Verlag: 1971; Vol. 2, Part 1, pp 451-452.

(28) Bevington, P. R. Data Reduction and Error Analysis for the Physical Sciences; McGraw-Hill: New York, 1969. 
measurement had the same relative standard deviation and determined this relative standard deviation and the standard deviations of the parameters in the usual manner by assuming a good fit. In reality, of course, the error distribution may not be Gaussian, and data points obtained at different physical conditions may have a different relative error, which limits the usefulness of the presented standard deviations as a measure for the random error. We always present standard deviations when we determine parameters from data but give no error estimate of the final result.

Simulation of Relaxation Spectra. The fundamental reference of the theory of relaxation kinetics is Eigen and De Maeyer. ${ }^{13}$ Many other treatments are available. ${ }^{1,11,15,22,29}$ Since we frequently calculate the $\Gamma$ factor of the amplitude in this work, we state its formula for a single relaxation process explicitly:

$$
\Gamma=1 /\left(\sum_{i} \nu_{i}^{2} / \bar{c}_{i}\right)
$$

where $\nu_{i}$ is the stoichiometric coefficient of species $i$ and $\bar{c}_{i}$ is the equilibrium concentration of species $i$.

We also want to clarify a technical detail. Relaxation times of coupled chemical equilibria cannot cross because of the nature of the linearized rate matrix. This is closely related to the nocrossing rule of quantum chemistry. Instead of actually crossing, each inverse relaxation time (eigenvalue) bends back and continues seemingly as a continuation of the other one. The two relaxation times exchange amplitudes (eigenvectors), however. Therefore, relaxation times associated with particular normal reactions appear to cross.

Ultrasound Absorption. We measured the ultrasound absorption in the frequency range from 0.2 to $20 \mathrm{MHz}$, using a resonator cell described by Eggers and Funck. ${ }^{30}$ The measurements were done as described by Eggers. ${ }^{19}$ We describe only the evaluation of the ultrasound amplitudes. The result of the

(29) Bauer, H. J. In Physical Acoustics; Mason, W. P., Ed.; Academic: New York, 1965; Vol. IIA, p 47.

(30) Eggers, T.; Funck, T. Rev. Sci. Instrum. 1973, 44, 969-977. measurement is the absorption peak width, in units of frequency, at half power divided by the ultrasound frequency at the maximum of the absorption curve. For a single relaxation process, we have at the frequency of maximal absorption

$$
(\Delta f /)_{\tau^{-1}=2 \pi f}=\Gamma \Delta V_{\mathrm{S}}^{2} /\left(2 R T \kappa_{0}\right)
$$

Substituting the standard value for the gas constant $R, 298.15$ $\mathrm{K}$ for the absolute temperature $T$, and the value of water for the isothermic compressibility $\kappa_{0}$, we obtain

$$
(\Delta f / f)_{\tau^{-1}=2 \pi f}=4.44 \times 10^{-4} \Gamma \Delta V_{\mathrm{S}}^{2}
$$

where $\Gamma$ has the dimension of a concentration, liters per mole, and $\Delta V_{\mathrm{S}}$, the adiabatic reaction volume, is given in milliters per mole. The amplitudes of the simulations yield $\Gamma \Delta V_{\mathrm{S}}{ }^{2}$. Finally, we have the following relation between adiabatic and isothermic reaction volumes:

$$
\Delta V_{\mathrm{S}}=\Delta V-\Delta H \alpha_{p} /\left(\rho C_{p}\right)
$$

Using again the values of water for the thermic expansion coefficient $\alpha_{p}$, the density $\rho$, and the heat capacity $C_{p}$, we have

$$
\Delta V_{\mathrm{S}}=\Delta V-\left(6.7 \times 10^{-5}\right) \Delta H
$$

where $\Delta V$, the reaction volume at constant pressure and temperature, has the unit milliliters per mole, and $\Delta H$, the reaction enthalpy at constant pressure and temperature, has the unit joules per mole. Analogous relations apply in the case of more than one relaxation process.

Acknowledgment. The work in Vienna has been supported financially by the Austrian Fonds zur Förderung der wissenschaftlichen Forschung (Project No. 2015 and 3388). Johannes Reiter received a stipend from the Max-Planck-Society to visit the Max-Planck-Institut für Biophysikalische Chemie in Göttingen. He thanks the group of Professor M. Eigen for their hospitality and their support.

Registry No. 3-Hydroxypyridine, 109-00-2; anthranilic acid, 118-92-3. 